\title{
A Platform To Enhance Quantitative Single Molecule Localization Microscopy
}

Ottavia Golfetto, ${ }^{\dagger}$ Devin L. Wakefield, ${ }^{\dagger}$ Eliedonna E. Cacao, Kendra N. Avery, Victor Kenyon, Raphael Jorand, Steven J. Tobin, Sunetra Biswas, Jennifer Gutierrez, Ronald Clinton, Yuelong Ma, David A. Horne, John C. Williams, ${ }^{\circledR}$ and Tijana Jovanović-Talisman*

Department of Molecular Medicine, Beckman Research Institute, City of Hope, 1500 East Duarte Road, Duarte, California 91010, United States

\section{Supporting Information}

ABSTRACT: Quantitative single molecule localization microscopy (qSMLM) is a powerful approach to study in situ protein organization. However, uncertainty regarding the photophysical properties of fluorescent reporters can bias the interpretation of detected localizations and subsequent quantification. Furthermore, strategies to efficiently detect endogenous proteins are often constrained by label heterogeneity and reporter size. Here, a new surface assay for molecular isolation (SAMI) was developed for qSMLM and used to characterize photophysical properties of fluorescent proteins and dyes. SAMIqSMLM afforded robust quantification. To efficiently detect endogenous proteins, we used fluorescent ligands that bind to a

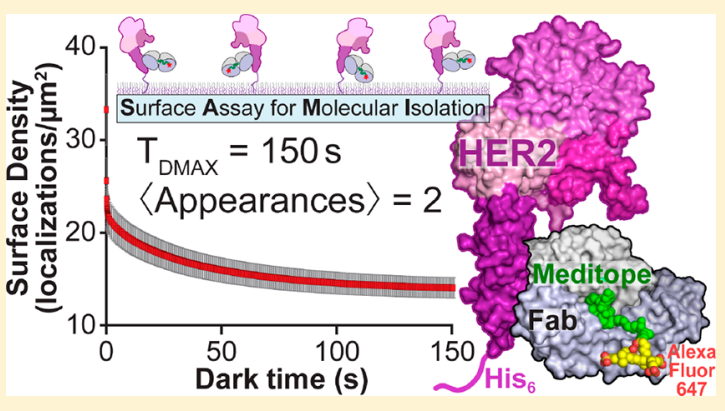
specific site on engineered antibody fragments. Both the density and nano-organization of membrane-bound epidermal growth factor receptors (EGFR, HER2, and HER3) were determined by a combination of SAMI, antibody engineering, and paircorrelation analysis. In breast cancer cell lines, we detected distinct differences in receptor density and nano-organization upon treatment with therapeutic agents. This new platform can improve molecular quantification and can be developed to study the local protein environment of intact cells.

\section{INTRODUCTION}

Biological molecules can be imaged at the nanoscale by single molecule localization microscopy (SMLM) methods. ${ }^{1}$ SMLM is particularly useful for studying how protein stoichiometry and organization regulate biological processes on the plasma membrane. The scale of such processes range from the assembly of individual protein complexes to the formation of large signaling networks. To obtain detailed information on molecular composition, SMLM images must be properly quantified. Despite significant method advancements, determining protein nano-organization and molecular density using quantitative SMLM (qSMLM) remains challenging.

In SMLM, target molecules of interest are detected with fluorescent reporters. Two examples of reporters include optical highlighter proteins and antibodies labeled with photoswitchable dyes. These reporters have intricate photophysical properties. Before they irreversibly photobleach, fluorophores cycle between a dark and fluorescent state (photoblinking). ${ }^{2,3}$ These switching cycles are complex. ${ }^{4,5}$ Both the molecular structure of the fluorophore and the imaging conditions (e.g., optical path and specifics of fluorophore activation) can influence the detected number of localizations. ${ }^{6,7}$ Thus, it can be difficult to relate the detected number of localizations from fluorescent reporters to the number of target proteins for counting single molecules.
Additional challenges can arise when target proteins are detected with fluorescently labeled antibodies. The following aspects need to be considered: (1) Antibodies need to be specific for their target protein (antigen). (2) Affinity labeling must be optimized to efficiently detect target proteins. (3) Fluorescent labeling must not interfere with antigen detection. (4) The labeling stoichiometry between the photoswitchable dyes and antibodies should be well-defined, preferably sitespecific and stoichiometric. This last point is important for robust molecular counting, but is often not appropriately considered. Most labeling protocols involve coupling dyes though lysines or cysteines on the antibody, which produces a nonstoichiometric, combinatorial distribution of labeled reporters. ${ }^{8}$ This can present several challenges for qSMLM imaging. For example, a single antibody may be labeled with multiple fluorophores. A high number of localizations are recorded in one position and this may result in inadvertent "overcounting" of the target molecule. Alternatively, inefficient fluorescent labeling of antibodies may result in "undercounting" of the target molecule. Moreover, an incomplete picture of target molecules may result from the failure to acquire data for a sufficient period of time.

Received: May 11, 2018

Published: September 26, 2018 
Table 1. Localization Densities with SEM from Different Surfaces Using SAMI-qSMLM

\begin{tabular}{|c|c|c|c|c|}
\hline & \multicolumn{3}{|c|}{ localizations $\left(\mu \mathrm{m}^{-2}\right)$} & \multirow[b]{2}{*}{$N$} \\
\hline & $488 \mathrm{~nm}$ & $561 \mathrm{~nm}$ & $647 \mathrm{~nm}$ & \\
\hline $50 \mu \mathrm{M} \mathrm{PEG-His}{ }_{6}$ & $0.07 \pm 0.04$ & $0.8 \pm 0.4$ & & 6 \\
\hline $50 \mu \mathrm{M} \mathrm{PEG}-\mathrm{His}_{6} \cdot 1 \mu \mathrm{M} \mathrm{His}_{6}$-PA-GFP & $0.4 \pm 0.2$ & & & 9 \\
\hline $1 \mathrm{nM} \mathrm{His}_{6}$-PA-GFP $\left(1: 100{\left.\mathrm{PEG}-\mathrm{His}_{6}\right)}\right.$ & $6 \pm 1$ & & & 9 \\
\hline $3 \mathrm{nM} \mathrm{His}_{6}$-PA-GFP (1:100 PEG-His 6 ) & $22 \pm 5$ & & & 6 \\
\hline $10 \mathrm{nM} \mathrm{His}_{6}$-PA-GFP (1:100 PEG-His 6 ) & $75 \pm 15$ & & & 9 \\
\hline $3 \mathrm{nM} \mathrm{His}_{6}$-PA-GFP (1:1000 PEG-His 6 ) & $0.62 \pm 0.08$ & & & 7 \\
\hline $3 \mathrm{nM} \mathrm{His}_{6}$-PA-GFP (1:10 PEG-His $\left.{ }_{6}\right)$ & $87 \pm 26$ & & & 6 \\
\hline $1 \mathrm{nM} \mathrm{His}_{6}$-PA-mCherry1 (1:100 PEG-His $\left.{ }_{6}\right)$ & & $5 \pm 1$ & & 9 \\
\hline 3 nM His $_{6}$-PA-mCherryl (1:100 PEG-His 6 ) & & $14 \pm 4$ & & 9 \\
\hline $3 \mathrm{nM} \mathrm{His}_{6}$-PA-GFP (1:100 PEG-His $\left.{ }_{6}\right) 3$ nM His ${ }_{6}$-PA-mCherry1 & $21 \pm 5$ & $0.6 \pm 0.3$ & & 8 \\
\hline $3 \mathrm{nM} \mathrm{His}_{6}$-PA-GFP + 3 nM PA-mCherryl (1:100 PEG-His 6 ) & $23 \pm 5$ & $0.9 \pm 0.2$ & & 8 \\
\hline 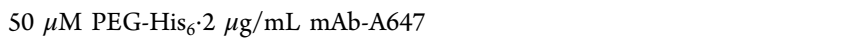 & & & $0.2 \pm 0.2$ & 5 \\
\hline $3 \mathrm{nM} \mathrm{His}_{6}$-PA-GFP (1:100 PEG-His $\left.{ }_{6}\right) 2 \mu \mathrm{g} / \mathrm{mL} \mathrm{mAb}-\mathrm{A} 647$ & & & $16 \pm 3$ & 10 \\
\hline $50 \mu \mathrm{M}$ PEG-His ${ }_{6} 2 \mu \mathrm{g} / \mathrm{mL} \mathrm{mAb}-$ Atto 488 & $1.9 \pm 0.2$ & & & 4 \\
\hline $3 \mathrm{nM} \mathrm{His}_{6}$-PA-mCherry1 (1:100 PEG-His $\left.{ }_{6}\right) 2 \mu \mathrm{g} / \mathrm{mL} \mathrm{mAb}-$ Atto488 & $16 \pm 2$ & & & 6 \\
\hline $50 \mu \mathrm{M} \mathrm{PEG}-\mathrm{His}_{6} 100 \mathrm{nM}$ trastuzumab meFab/M-A647 & & & $0.2 \pm 0.2$ & 3 \\
\hline $10 \mathrm{nM} \mathrm{His}_{6}$-HER2 (1:100 PEG-His $\left.{ }_{6}\right) 100 \mathrm{nM}$ trastuzumab meFab/M-A647 & & & $33 \pm 4$ & 12 \\
\hline $30 \mathrm{nM} \mathrm{His}_{6}$-HER2 (1:100 PEG-His 6 ) $100 \mathrm{nM}$ trastuzumab meFab/M-A647 & & & $109 \pm 18$ & 18 \\
\hline
\end{tabular}

SMLM analysis methods have been devised to address some of these challenges and improve single molecule counting. Effective strategies consider the average number of photoblinking events, ${ }^{2,9,10}$ use spatial and temporal thresholding on molecule localizations, ${ }^{11,12}$ or evaluate underlying photokinetic information. ${ }^{3,13}$ For example, the approach of Lee et al. ${ }^{3}$ aims to correct for overcounting by using known fluorophore photobleaching rates, photoblinking rates, and local molecular density. These parameters are used to both estimate an optimal global dark time and account for individual molecules. ${ }^{3}$ As demonstrated by other recent work, counting approaches can operate successfully under certain conditions without extensive knowledge of photophysical states. ${ }^{14,15}$ If every blinking event is recorded until all fluorophores in a particular spot bleach, the distribution of molecule numbers can be obtained from a binomial distribution. ${ }^{15,16}$

Similarly, single molecule imaging and quantification has benefited from new experimental methods. In general, these methods have been designed to accommodate specific applications. For example, DNA point accumulation for imaging in nanoscale topography (DNA-PAINT) features transient binding of fluorescent reporters as a way to decouple blinking events from dye photophysics. ${ }^{17,18}$ Despite the strengths of this method, extensive preparation is required to create complementary single-stranded DNA oligomers and ensure that these strands bind with the appropriate duration and specificity for image acquisition. Titration methods ${ }^{19,20}$ can also be performed to both calibrate the number of localizations per target molecule and assess the extent of molecular clustering. However, these methods necessitate collecting multiple SMLM data sets of cells at different labeling densities-a time-consuming task with results that may already be obtained from a single data set. $^{21}$ In other approaches, special attention to fluorophore photophysics $3,4,22$ and laser intensities ${ }^{23}$ have helped establish favorable SMLM imaging conditions. Recently, well-defined experimental parameters have been used to better determine the optimal resolution for a given localization microscope, ${ }^{24}$ but the application of these parameters to a cellular model has yet to be thoroughly tested.
Optical setup and imaging conditions vary greatly across SMLM methods. ${ }^{25-27}$ Thus, there is a need to develop systematic experimental approaches to characterize fluorescent reporters for a desired SMLM purpose and imaging condition. Here we present a straightforward strategy to define the photophysical properties of fluorescent reporters for counting single molecules. Since SMLM approaches utilize total internal reflection illumination to excite molecules proximal to coverslip surfaces, we have employed functionalized surfaces. Importantly, fluorescent reporters are isolated on these surfaces to allow for proper characterization of individual molecules in an approach we are calling a "surface assay for molecular isolation”, or SAMI. Using SAMI, optical highlighter proteins or other target proteins were covalently and sparsely attached to coverslips. Target proteins were subsequently affinity labeled with fluorescent antibodies. This allowed us to precisely determine the photophysical properties of fluorescent reporters for a given optical setup, labeling condition, and imaging condition. SAMI is compatible with different techniques [e.g., photoactivated localization microscopy (PALM) or direct stochastic optical reconstruction microscopy (dSTORM)] and any standard SMLM microscope. Notably, SAMI can be performed without specialized equipment, complementary imaging modalities, or (nano)fabricated substrates. Here, SAMI-qSMLM was used to improve molecular counting and determine the organization of endogenous proteins.

To efficiently detect endogenous proteins, we used highly specific antibodies and a novel engineering scheme to site specifically and stoichiometrically add fluorophores. Recently, we identified a cyclic peptide that binds within the Fab arm of cetuximab, the clinical mAb targeting the epidermal growth factor receptor. ${ }^{28}$ We have named this peptide a meditope. While the meditope binding site is unique to cetuximab, the residues within the $\mathrm{Fab}$ can be readily grafted onto mAbs including trastuzumab, pertuzumab, Okt3, and many others. $^{28-33}$ These engineered constructs are known as meditope-enabled mAbs (memAbs). Through extensive structure-function studies, the affinity of the interaction has been optimized to $<10 \mathrm{pM}$ at $25{ }^{\circ} \mathrm{C}$. Moreover, in all cases 

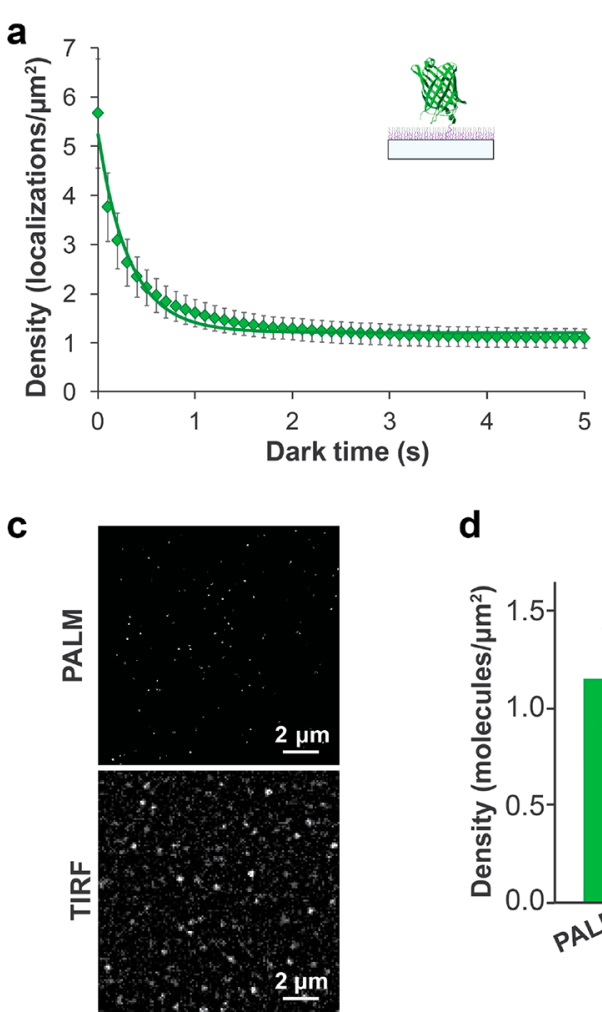

d
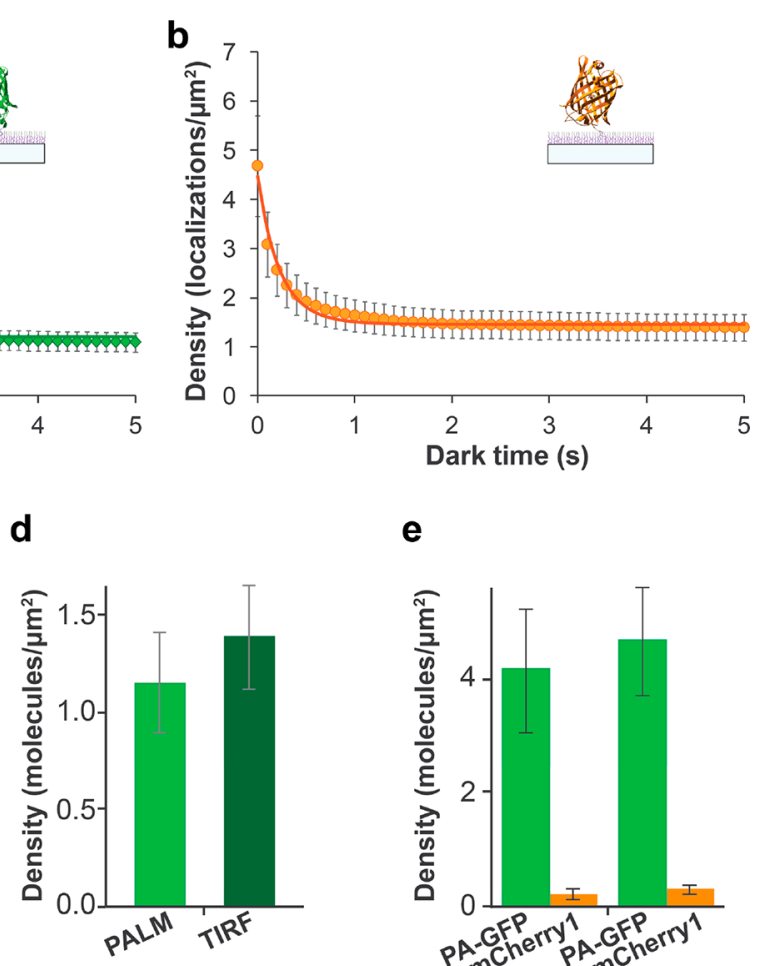

e

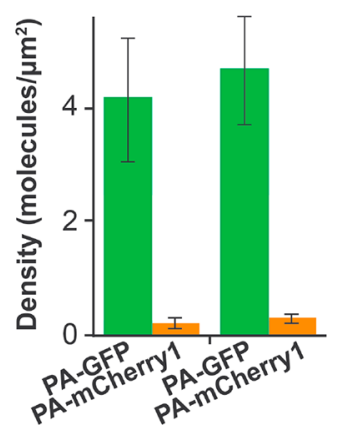

Figure 1. Counting molecules on surfaces using SAMI and PALM imaging. (a) Localization density of $1 \mathrm{nM} \mathrm{His}_{6}$-PA-GFP surfaces as a function of dark time (green diamonds are individual data points). Solid line represents a fit using a semiempirical equation. ${ }^{2,3}$ Extracted data: $\alpha=5, T_{\mathrm{DMAX}}=5$ $\mathrm{s}, T_{\mathrm{OFF}}=(0.34 \pm 0.02) \mathrm{s}$. (b) Localization density of $1 \mathrm{nM}$ PA-mCherryl surfaces as a function of dark time (orange diamonds are individual data points). Solid line represents a fit using a semiempirical equation. ${ }^{2,3}$ Extracted data: $\alpha=3, T_{\mathrm{DMAX}}=5 \mathrm{~s}, T_{\mathrm{OFF}}=(0.26 \pm 0.03) \mathrm{s}$. (c) PALM image of a representative surface coated with $1 \mathrm{nM} \mathrm{His}_{6}$-PA-GFP (top) and TIRF image of a representative surface coated with $1 \mathrm{nM} \mathrm{His} 6_{6}$-eGFP (bottom). (d) Density quantification of the surfaces imaged with PALM and TIRF ( $N=9$ ROIs for PALM and $N=18$ ROIs for TIRF), $p=0.4$. (e) Binding sites on functionalized surfaces are saturated. We first used $3 \mathrm{nM} \mathrm{His}_{6}$-PA-GFP to make surfaces as described in Methods. After washing with PBS, surfaces were incubated with $3 \mathrm{nM} \mathrm{His}_{6}$-PA-mCherryl. Imaging confirmed unperturbed signal in the $488 \mathrm{~nm}$ channel and minimal signal in the 561 $\mathrm{nm}$ channel (two left bars, green and orange). Surfaces preferentially bind His-tagged proteins. Surfaces were incubated with both $3 \mathrm{nM}$ His ${ }_{6}$-PAGFP and $3 \mathrm{nM}$ PA-mCherryl together. Imaging confirmed unperturbed signal in the $488 \mathrm{~nm}$ channel and minimal signal in the $561 \mathrm{~nm}$ channel (two right bars, green and orange). All error bars represent standard error of the mean (SEM).

thus far, we have shown that the antigen binding is indistinguishable in the presence or absence of the meditope and is comparable to the parental $\mathrm{mAb} .^{29,34}$

Here, we used fluorescently labeled meditopes complexed with memAbs as SMLM reporters. The labeling of memAbs with fluorescent meditopes is both stoichiometric and site specific, forming a homogeneous complex. Since the apparent distance between a typical fluorescent antibody reporter and its target molecule is large $(\sim 10 \mathrm{~nm}){ }^{35}$ meditope-enabled Fab fragments $(\mathrm{meFab})$ were used to bring fluorophores closer $(\sim 4$ $\mathrm{nm})^{28}$ to the target molecule and improve the overall localization of target molecules.

We have combined SAMI, mAb engineering, and paircorrelation analysis ${ }^{9,36}$ of SMLM data into one platform. In this manner, we robustly determined the molecular organization of endogenous human epidermal growth factor receptor 2 (HER2) on the plasma membrane of cultured cell lines in steady state and upon treatment with two small molecule therapeutics. This was accomplished using trastuzumab meFab complexed with fluorescent meditope as a reporter. Moreover, we determined the organization of epidermal growth factor receptor (EGFR) and human epidermal growth factor receptor 3 (HER3) using the dual-targeting duligotuzumab ${ }^{37}$ as a meFab and memAb. Ultimately, this platform aims to make the quantification of target proteins more straightforward and accessible to interested SMLM users.

\section{RESULTS AND DISCUSSION}

SAMI Design: Optical Highlighter Proteins. To determine the photophysical properties of optical highlighter proteins, we first designed several reagents with a His-tag. We cloned and purified monomeric His-tagged fluorescent or photoactivatable proteins containing the same linker sequence (Figures $\mathrm{S} 1$ and $\mathrm{S} 2 \mathrm{a}$ ). This linker sequence is relatively long ( 31 amino acids between the $\mathrm{His}_{6}$ tag and protein) to enable unrestricted fluorophore rotation. This mobility is important for proper localization in SMLM. ${ }^{38}$ We also synthesized a Histagged polyethylene glycol (PEG-His 6 ).

We next developed a protocol for the covalent attachment of His-tagged proteins compatible with SMLM (Scheme S1, see Methods for details). Modified surfaces were immediately used for imaging and results from multiple experiments are summarized in Table 1.

PEG-His ${ }_{6}$ surfaces had minimal background in all channels when standard SMLM imaging conditions were used (Table 1). Moreover, the addition of PA-GFP or antibodies labeled with Alexa Fluor 647 (AF647) or Atto 488 (A488) to PEG$\mathrm{His}_{6}$ surfaces did not lead to appreciable signal. The absence of signal indicated that PEG coated surfaces significantly reduced, 

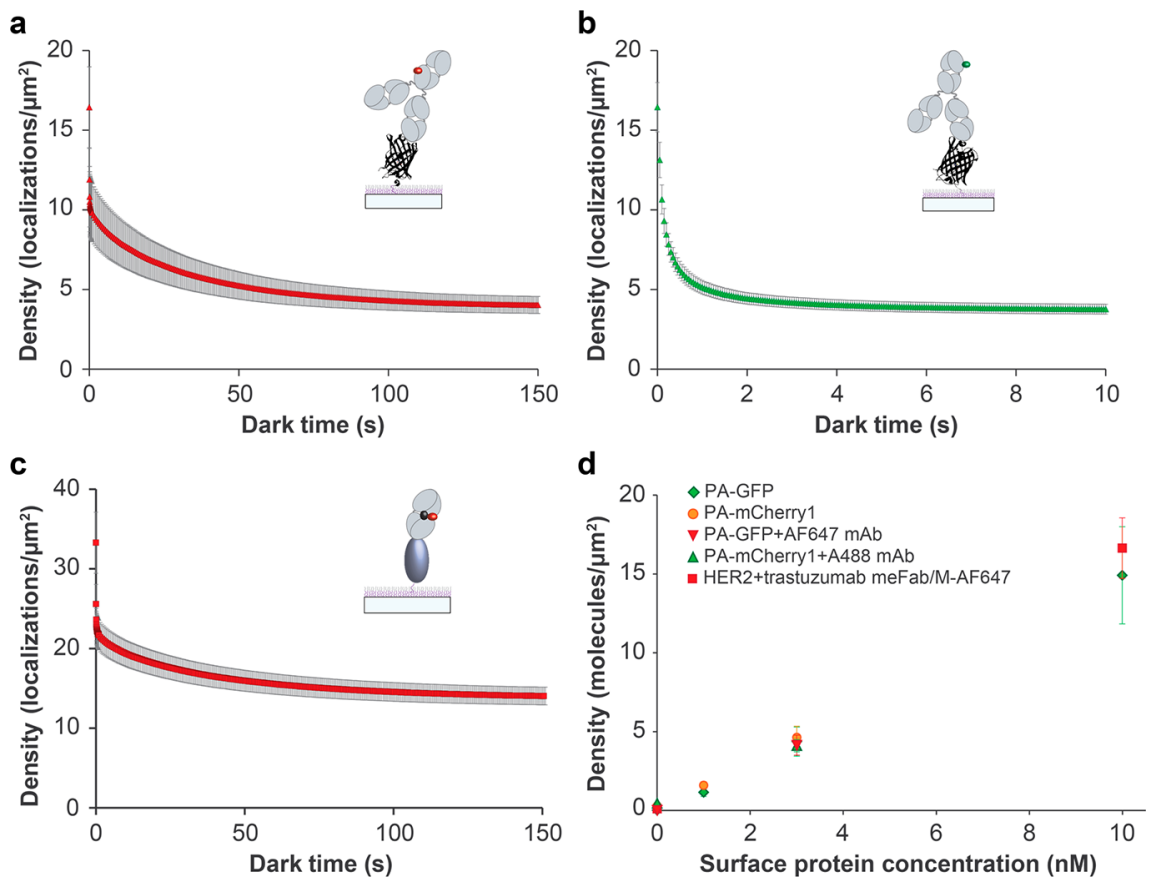

Figure 2. Counting molecules on surfaces using SAMI-qSMLM. (a) Localization density of $3 \mathrm{nM} \mathrm{His}{ }_{6}$-PA-GFP and AF647 labeled mAb surfaces as a function of dark time: $\alpha=4, T_{\text {DMAX }}=150 \mathrm{~s}$. (b) Localization density of $3 \mathrm{nM} \mathrm{His}{ }_{6}$-PA-mCherryl and A488 labeled mAb surfaces as a function of dark time: $\alpha=4, T_{\text {DMAX }}=10 \mathrm{~s}$. (c) Localization density of $10 \mathrm{nM} \mathrm{His}_{6}$-HER2 and $100 \mathrm{nM}$ trastuzumab meFab/M-AF647 surfaces as a function of dark time: $\alpha=2, T_{\text {DMAX }}=150 \mathrm{~s}$. (d) Density of detected molecules as a function of surface protein concentration. $R^{2}$ value (linear fit) for all measured fluorophores and protein concentrations (Table 1 and Figure S8) is 0.992. Slope and intercept have values of 1.56 and -0.05 , respectively. All error bars represent SEM.

if not completely prevented, adventitious binding (PEG coated surfaces had nonfouling properties). By combining His-tagged proteins and PEG-His 6 in specific ratios, we detected a different number of localizations (fluorophore appearances) via SMLM imaging. Our results show that an increase in a specific protein concentration led to an increase in signal, whereas an

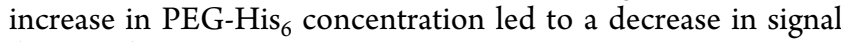
(Table 1). This demonstrated that His-tagged proteins were attached to surfaces in a concentration dependent manner.

Next, we found conditions that led to sparse surface attachment of fluorophores (one molecule or fewer in a diffraction-limited spot). Pair-correlation analysis was used to show that under these conditions our surfaces displayed a random distribution of fluorophores (Figure S3). These surfaces were used to determine the photophysical properties of fluorophores under conditions typically used for SMLM

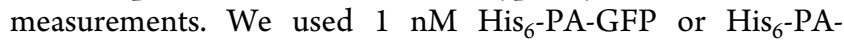
mCherryl with 100 fold $\mathrm{PEG}-\mathrm{His}_{6}$ for initial characterization. After standard SMLM image processing, ${ }^{39}$ we generated plots to show localization densities as a function of dark time (see Methods for details). The point at which an increase in dark time became invariable with density (defined as the maximum dark time, $\left.T_{\mathrm{DMAX}}\right)$ was extracted using a bisection point calculation (Figure S4). For both PA-GFP and PA-mCherryl, $T_{\text {DMAX }}$ was determined to be $5 \mathrm{~s}$. To obtain the average number of fluorophore localizations $(\alpha)$, we divided the total number of detected localizations by the number of localizations obtained after grouping using the $T_{\text {DMAX }}$. We obtained an $\alpha$ of 5 for PA-GFP and an $\alpha$ of 3 for PA-mCherryl. We applied a semiquantitative equation ${ }^{2,3}$ to confirm these values and extracted a fluorescence off-time $\left(T_{\mathrm{OFF}}\right)$, illustrated by the fits in Figure 1a,b. Similar results were obtained when $3 \mathrm{nM}$ His-tagged proteins were combined with 100 fold PEG-His 6
(Figure S5). Blinking of PA-mCherry1 is illustrated in Figure S6.

In addition to fluorophore blinking, the photoactivation efficiency of optical highlighter proteins can contribute to counting uncertainties in PALM. Photoactivation efficiency can depend on imaging conditions and experimental setup. However, $488 \mathrm{~nm}$ activation of PA-GFP is generally efficient (e.g., $\sim 72 \%$ photoactivation efficiency has been reported with relatively low $488 \mathrm{~nm}$ laser power). ${ }^{40}$ Here, we compared the imaging of single molecules with PALM (using PA-GFP as a reporter) and TIRF (using eGFP as a reporter). Representative images of these surfaces are shown in Figure 1c and corresponding densities are shown in Figure 1d. SAMIqSMLM and TIRF densities were similar (Figure 1d), suggesting that our approach can provide for robust molecule counting.

We demonstrated that binding sites on functionalized surfaces were saturated. Three $\mathrm{nM} \mathrm{\textrm {His } _ { 6 }}$-PA-mCherryl was incubated on surfaces already coated with $3 \mathrm{nM} \mathrm{His}$-PA-GFP. Imaging confirmed unperturbed signal in the $488 \mathrm{~nm}$ channel and minimal signal in the $561 \mathrm{~nm}$ channel (Figure 1e, two left bars). We further demonstrated that SAMI surfaces preferentially bind His-tagged proteins. Surfaces were incubated with 3 $\mathrm{nM} \mathrm{His}{ }_{6}$-PA-GFP and $3 \mathrm{nM}$ PA-mCherryl and then washed. Only PA-GFP was observed by PALM. Moreover, the presence of PA-mCherryl did not perturb the number of localizations of PA-GFP. The results suggest that this assay is selective for Histagged molecules and unperturbed by nonspecific proteins (Figure 1e, two right bars).

Finally, to show that photophysical parameters obtained with SAMI can be translated to cell environments, we evaluated the distribution of two model proteins, glycosylphosphatidylinositol-anchored protein (GPI) and vesicular 
stomatitis viral glycoprotein (VSVG) using pair-correlation analysis. The average number of fluorophore localizations $(\alpha)$ serves as a necessary parameter for the pair-correlation analysis calculation of protein cluster organization ${ }^{9,36}$ (see Figure S7 caption for details). We used $\alpha$ values from SAMI that reflected equivalent imaging conditions used for cell experiments. The occupancy of clusters with GPI or VSVG (Figure S7) showed excellent agreement with the literature. $9,41-44$

SAMI Design: Fluorescently Labeled Antibodies and Antibody Fragments. Our assay can be extended to dSTORM measurements using fluorescently labeled antibodies to detect proteins covalently attached to surfaces. AF647 labeled anti-GFP antibody was used to detect PA-GFP and A488 labeled anti-RFP antibody was used to detect PAmCherry1. We obtained localization density vs dark time plots and extracted relevant information. AF647 had a $T_{\mathrm{DMAX}}$ of 150 $\mathrm{s}$ (Figure $2 \mathrm{a}$ ) and $\mathrm{A} 488$ had a $T_{\text {DMAX }}$ of $10 \mathrm{~s}$ (Figure $2 \mathrm{~b}$ ). In both cases, $\alpha$ was 4 . Accounting for the stoichiometry between antibodies and fluorophores, resulting information on fluorophore photophysical properties enabled the effective counting of these target fluorescent proteins.

We next functionalized surfaces with His-tagged HER2 protein and used meditope-AF647 (M-AF647) complexed with trastuzumab meFab as a reporter (see Methods). As with AF647 labeled antibodies, we obtained a $T_{\text {DMAX }}$ of $150 \mathrm{~s}$, but now $\alpha$ was 2 (Figure 2c). The change in $\alpha$ between AF647 labeled anti-GFP antibody and trastuzumab meFab/M-AF647 likely reflects the difference in labeling approaches and the degree of labeling (see Methods). Since the interaction between meditopes and meFabs is extremely tight and specific, assessment of the reporter was quite reliable and did not need to be repeated for every labeled batch as long as the same imaging conditions were used. Finally, using the corresponding values for $\alpha$, we calculated the molecular density for each investigated reporter at a given surface protein concentration. Excellent correlation was obtained (Figure 2d and Figure S8). The impact of using the appropriate average number of fluorophore appearances from SAMI is shown in Figure S8. Comparing the variance in localization density to the variance in $\alpha$-adjusted localization density revealed a significant difference.

Imaging with Meditope Reagents. In addition to the synthesized M-AF647 just described, we prepared a meditopeprotein L-PA-GFP (MPL-PA-GFP) construct, an ultrahigh affinity meditope variant purified from bacterial cultures. ${ }^{29}$ We mixed trastuzumab meFab with excess of either of these fluorescent meditopes, purified the resulting complexes, and used these complexes immediately for imaging. Excellent signal-to-noise was obtained and a representative BT-474 cell imaged with trastuzumab meFab/M-AF647 is shown in Figure 3a. In Figure $3 b$, a model of meFab/meditope complexes bound to the extracellular domain of HER2 is shown. To characterize their binding properties, we calculated effective binding constants for both meditope complexes (Figure 3c). The effective binding constant was in the low nanomolar range for both reagents. However, the number of detected proteins at saturation was different: bulkier MPL-PA-GFP had fewer binding sites compared to M-AF647. SPR measurements (Figure S9) and qSMLM on HER2-functionalized surfaces (Figure S10) confirmed that MPL-PA-GFP did not significantly alter the binding constant between meFab and HER2.

To better understand this difference, we applied quantitative analysis to calculate the detected receptor density and the a

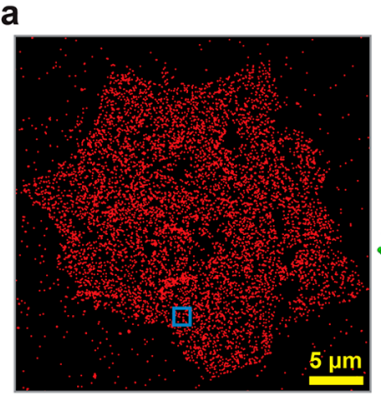

b
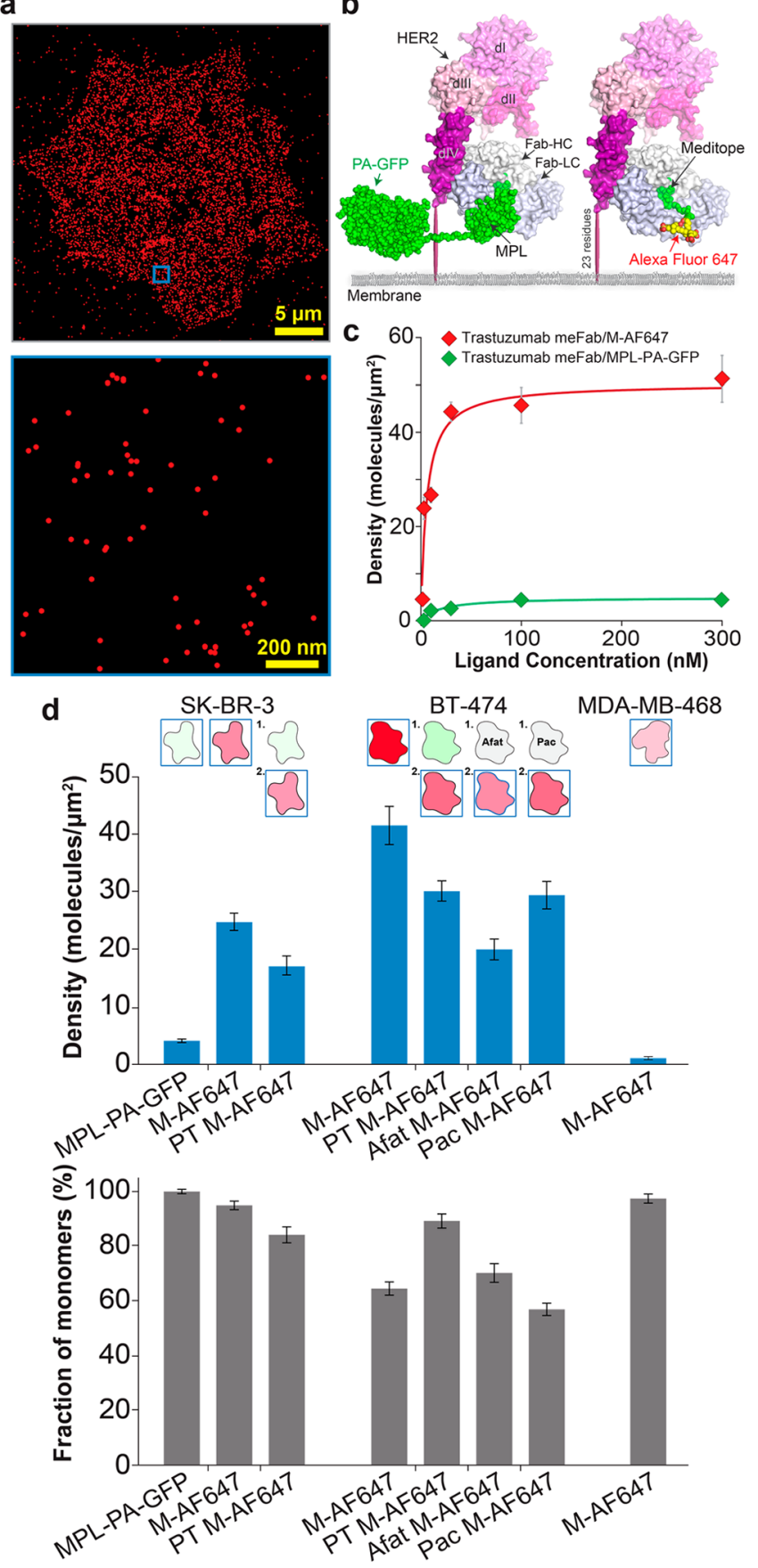

Figure 3. Detection of endogenous HER2 receptors in BT-474, SKBR-3, and MDA-MB-468 cells with trastuzumab meFab reagents. (a) Representative BT-474 cell (top), with zoomed-in region (bottom), labeled with trastuzumab meFab/M-AF647. Images were prepared using MATLAB to plot all localizations. (b) Model showing the binding of meditope constructs to the extracellular domain of HER2. Model design based on available crystal structures and secondary structure prediction tools. (c) Comparison of binding curves with trastuzumab meFab/MPL-PA-GFP complex in SK-BR-3 cells (green: effective $K_{\mathrm{D}}=19.4 \pm 0.6 \mathrm{nM}, N_{\text {sat }}=5$ molecules $\left./ \mu \mathrm{m}^{2} ; R^{2}=0.94\right)$ and trastuzumab meFab/M-AF647 in BT-474 cells (red: effective $K_{\mathrm{D}}=$ $6.2 \pm 0.3 \mathrm{nM}, N_{\text {sat }}=50$ molecules $\left./ \mu \mathrm{m}^{2} ; R^{2}=0.94\right)$. (d) Density of HER2 receptors (top, blue) and fraction of monomers (bottom, gray). HER2 is detected by either trastuzumab meFab/MPL-PA-GFP in SK-BR-3 cells or trastuzumab meFab/M-AF647 in SK-BR-3, BT474, and MDA-MB-468 cells. For density: p MPL-PA-GFP) < 0.05; $\mathrm{p}_{\mathrm{M}-\mathrm{AF} 647}(\mathrm{SK}-\mathrm{BR}-3$ vs BT-474 $)<0.001$. For 
Figure 3. continued

fraction of monomers: p $_{\text {SK-BR-3 }}($ M-AF647 vs MPL-PA-GFP $)=0.6$; $\mathrm{p}_{\mathrm{M}-\mathrm{AF} 647}(\mathrm{SK}-\mathrm{BR}-3$ vs BT-474) $<0.001$. In a subset of measurements, cells were pretreated (PT) with trastuzumab meFab/MPL-eGFP and HER2 was detected using trastuzumab meFab/M-AF647. eGFP fluorescence was confirmed for each cell. For density: $\mathrm{p}_{\mathrm{SK}-\mathrm{BR}-3 ; \mathrm{M}-\mathrm{AF} 647}$ (PT vs untreated) < 0.01; $\mathrm{p}_{\mathrm{BT}-474, \mathrm{M}-\mathrm{AF} 647}(\mathrm{PT}$ vs untreated) $<0.01$. For fraction of monomers: $\mathrm{P}_{\mathrm{SK}-\mathrm{BR}-3 ; \mathrm{M}-\mathrm{AF} 647}(\mathrm{PT}$ vs untreated $)<0.001$; $\mathrm{p}_{\mathrm{BT}-474 ; \mathrm{M}-\mathrm{AF} 647}(\mathrm{PT}$ vs untreated $)<0.001$. Testing two therapeutic drugs, BT-474 cells were treated with either $100 \mathrm{nM}$ afatinib (Afat) or $100 \mathrm{nM}$ paclitaxel (Pac) prior to using trastuzumab meFab/M-AF647 to detect HER2. For density: $\mathrm{p}_{\mathrm{BT}-474}$ (Afat vs untreated) < 0.001; $\mathrm{p}_{\mathrm{BT}-474}$ (Pac vs untreated $)<0.05$. For fraction of monomers: $\mathrm{p}_{\mathrm{BT}-474}$ (Afat vs untreated) $<0.01 ; \mathrm{p}_{\mathrm{BT}-474}(\mathrm{Pac}$ vs untreated $)<0.01$. All error bars represent SEM.

fraction of receptor monomers (Figure 3d). BT-474 cells had a higher density and a lower fraction of HER2 monomers compared to SK-BR-3 cells when meFab/M-AF647 was used as a reporter. HER2-negative MDA-MB-468 cells ${ }^{45}$ had a very low HER2 density with mostly HER 2 monomers detected. As anticipated from the model and binding data, SK-BR-3 cells had a low density of HER2 when meFab/MPL-PA-GFP was used as a reporter. Cluster analysis revealed primarily HER2 monomers in this case. Next, we saturated HER2 with meFab/ MPL-eGFP complex in SK-BR-3 and BT-474 cell lines and used meFab/M-AF647 complex to detect the presence and distribution of any remaining unbound receptors. In both cell lines, we detected meFab/M-AF647 complex albeit at a reduced density as anticipated (Figure 3d, top). We expected that monomeric HER2 should be more accessible. However, qSMLM data (Figure 3d, bottom) suggests that meFab/MPLeGFP does not exclusively target monomeric receptors. In pretreated cells, the meFab/M-AF647 complex detected more monomers for BT-474 cells and less for SK-BR-3 cells. These experiments indicate that the local environment of HER2 is complex and unique, at least in the two cell lines presented here.

We next investigated the effects of two small molecule therapeutics on HER2 membrane density and organization. We tested acute treatments of afatinib (targeted therapy that acts as an irreversible inhibitor of HER2 and EGFR) ${ }^{46}$ and paclitaxel (chemotherapy that stabilizes microtubules). ${ }^{47}$ While both drugs significantly reduced HER2 density, afatinib had a more pronounced effect (Figure 3d, top). Interestingly, while afatinib decreased HER2 clustering (small increase in HER2 monomers), paclitaxel increased HER2 clustering (small decrease in HER2 monomers), shown in Figure 3d, bottom.

To extend our study to other growth factor receptors, we engineered duligotuzumab memAb to detect both HER3 and EGFR $^{37}$ Characterization of this memAb is shown in Figure S11. A representative MDA-MB-468 cell imaged with duligotuzumab meFab/M-AF647 is shown in Figure 4a. The density and organization of HER3 and EGFR detected with meFab duligotuzumab in BT-474 and MDA-MB-468 cells is shown in Figure 4b. BT-474 cells have low expression of HER3 and $\mathrm{EGFR}^{48}$ and thus showed low detected density with receptors organized primarily as monomers. MDA-MB-468 cells have low expression of HER3, but high expression of EGFR, $^{48}$ and thus showed high detected density with significant receptor clustering. In MDA-MB-468 cells, pretreatment with cetuximab Fab (blocking EGFR binding sites, but not HER3), led to a significant decrease in density and an

\section{a}
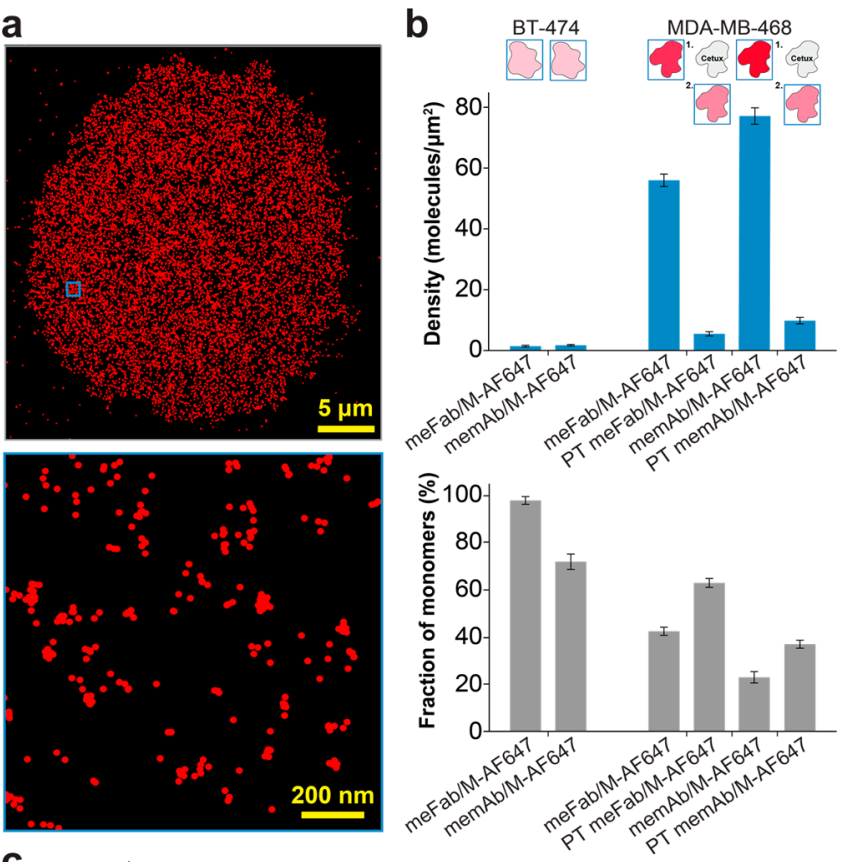

C

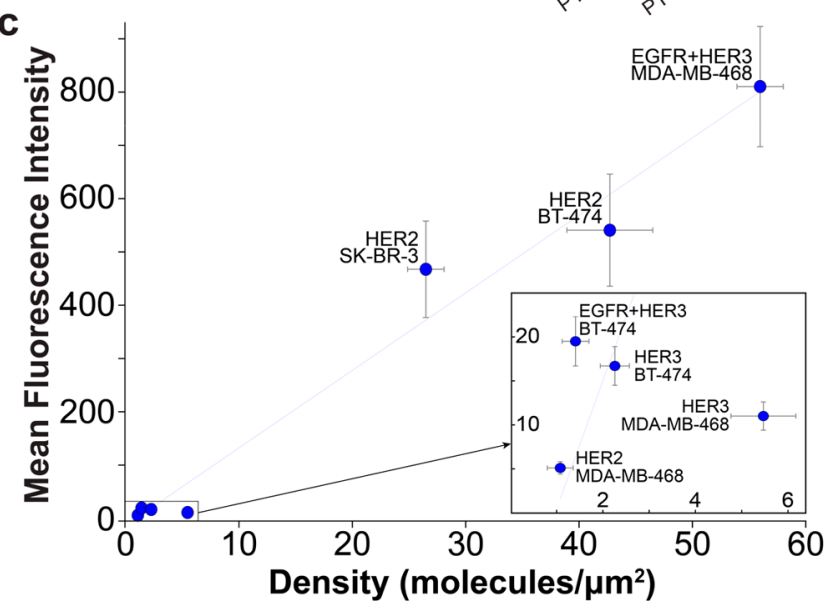

Figure 4. Detection of endogenous EGFR and HER3 receptors using duligotuzumab meFab and memAb. (a) Representative MDA-MB468 cell (top), with zoomed-in region (bottom), stained with duligotuzumab meFab/M-AF647. Images were prepared using MATLAB to plot all localizations. (b) Density of EGFR and HER3 receptors (top, blue) and fraction of monomers (bottom, gray). EGFR+HER3 are detected by either duligotuzumab meFab/MAF647 or duligotuzumab memAb/M-AF647 in BT-474 and MDAMB-468 cells. In MDA-MB-468 cells, cetuximab Fab pretreatment (PT) was used to enable detection of HER3 receptors alone by either duligotuzumab meFab/M-AF647 or duligotuzumab memAb/MAF647. For density: $\mathrm{p}_{\mathrm{BT}-474}\left(\mathrm{meFab}\right.$ vs memAb) $=0.1$; $\mathrm{p}_{\text {MDA-MB- } 468}$ $\left(\mathrm{meFab}\right.$ vs memAb) < 0.001; $\mathrm{p}_{\mathrm{MDA}-\mathrm{MB}-468}(\mathrm{meFab}$ vs PT meFab $)<$ $0.001 ; \mathrm{p}_{\text {MDA-MB-468 }}($ memAb vs PT memAb) $<0.001$. For fraction of monomers: $\mathrm{p}_{\mathrm{BT}-474}\left(\mathrm{meFab}\right.$ vs memAb) $<0.001 ; \mathrm{p}_{\mathrm{MDA}-\mathrm{MB}-468}(\mathrm{meFab}$ vs memAb) < 0.001; p pDA-MB-468 $($ meFab vs PT meFab) $<0.001$; $\mathrm{p}_{\mathrm{MDA}-\mathrm{MB}-468}(\mathrm{memAb}$ vs PT memAb) $<0.001$. All error bars represent SEM (c) Comparison of SAMI-qSMLM detected densities (data from Figure $3 \mathrm{~d}$ and Figure $4 \mathrm{~b}$ ) with previously published flow cytometry data $^{48}$ on the expression (mean fluorescence intensity) of different growth factor receptors. A linear fit to the data provides an $R^{2}$ value of 0.975. Slope and intercept have values of 14.55 and -14.01 , respectively. All error bars represent standard deviation.

increase in the fraction of monomers. When duligotuzumab memAb was used as a reporter, an increase in density and 
clustering was observed in MDA-MB-468 cells. As with meFab, pretreatment with cetuximab Fab in MDA-MB-468 cells led to a significant reduction in density and clustering.

To show the utility of our approach for robust receptor counting, we correlated the densities of trastuzumab meFab (detecting HER2 in three cell lines), duligotuzumab meFab (detecting EGFR + HER3 in two cell lines), and duligotuzumab meFab after cetuximab Fab pretreatment (detecting HER3 in two cell lines) with published values for mean fluorescence intensities. ${ }^{48}$ Excellent correlation was obtained (Figure 4c).

\section{DISCUSSION}

We have developed an innovative method for enhancing molecular counting in qSMLM by defining the photophysical properties of fluorescent molecules with SAMI. Our assay uses coverslips with covalently attached fluorescent molecules sparsely distributed across the surface. We used specific surface chemistry, as opposed to protein adsorption, and thus efficient and tunable binding of His-tagged proteins to coverslips was achieved with well-defined densities (Table 1) and orientations. ${ }^{49}$ In addition, surfaces were covered with PEG to reduce nonspecific protein attachment and provide for minimal background signal. This combination of features allowed us to assign fluorescence during SMLM imaging to a particular molecule and to precisely define traditionally elusive photophysical properties, such as the average number of localizations per fluorophore and the maximum dark time (time a molecule spends in a dark state without generating fluorescence) $)^{2,3}$ (Figures 1a,b, 2a,b,c). Importantly, using this approach, we have also shown that the detection efficiency with SMLM is high (Figure $1 \mathrm{c}, \mathrm{d}$ ), that all sites are saturated, and that His-tagged constructs can be preferentially attached (Figure 1e). We demonstrated that this method is compatible with optical highlighter proteins and fluorescently labeled proteins. Thus, SAMI could be readily used with other reporter molecules not tested here. Importantly, we observed a correlation between detected density and surface protein concentration for all investigated fluorescent reporters (Table 1 and Figure 2d). Two model proteins expressed in cells, GPI and VSVG, were used to validate our enhancements to qSMLM $^{9,41-44}$ (Figure S7).

Conventional labeling of $\mathrm{mAbs}$ with fluorescent dyes via lysines or cysteines produces a heterogeneous mixture ${ }^{8}$ wherein dyes can decorate the Fab framework, the Fc framework, and/or the CDR loops. Site-specific conjugation eliminates this issue. The meditope technology represents one approach to achieve site-specificity. The meditope site is within the Fab arm, the interaction has been engineered for ultrahigh affinity, and the presence of the meditope does not affect antigen binding. ${ }^{28}$ Importantly, the approach is compatible with virtually any fluorescent dye. Currently, more than 50 antibodies have been successfully meditope-enabled and a strategy to meditope-enable mAbs is published. ${ }^{33}$ All of these features illustrate that meditope technology can be readily adopted in the SMLM field.

SMLM platforms designed for the calibration and quantification of protein numbers have started to emerge. For example, a DNA origami based approach ${ }^{50}$ has been developed to provide site- and sequence-specific attachment points for single fluorophores or target proteins. This is ideal for the testing of a variety of labeling strategies and ultimately allows protein stoichiometries to be assessed within cellular contexts. The combination of SAMI-qSMLM and meditope technology compares favorably to this and other approaches as we demonstrate the biological utility of our platform.

Here, we focused on detecting growth factor receptors. Overexpression of these receptors is implicated in several forms of cancer and they represent important therapeutic targets. ${ }^{51,52}$ For example, both aberrant HER2 distributions ${ }^{53,54}$ and specific isoforms ${ }^{55}$ may be found in cancer cells and are implicated in therapeutic resistance. ${ }^{53-55}$ SAMI, meditope technology, and qSMLM can be combined to effectively assess nanoscale features of plasma membrane HER2.

We detected endogenous HER2 using a complex of trastuzumab meFab and meditope that contained either a synthetic dye (AF647) or a photoactivatable protein (PAGFP). This approach yielded a stoichiometric and site-specific labeling of the relatively small and highly specific trastuzumab meFab. Both meditope reagents were used in SMLM to detect endogenous HER2. We incorporated parameters from SAMI, and measured the affinity of fluorescent reporters on a single molecule level. On-cell $K_{\mathrm{D}}$ measurements are not true thermodynamic values. The cell can produce more receptors, alter the location of the receptor (internalize), alter the properties of the receptor (or ligand) through post-translational modification, or remove the receptor (and the ligand) through degradation (e.g., proteasomes). Despite these cellular effects, the quantification of specific interactions and assigning a value for an effective $K_{\mathrm{D}}$ is useful. Such values can be used to differentiate among a series of antibodies (ligands) that target a different epitope or bind more or less strongly to the same epitope. meFab complexes with both M-AF647 and MPL-PAGFP exhibited similar effective binding affinities to the antigen: effective $K_{\mathrm{D}}$ values were $6.2 \pm 0.6 \mathrm{nM}$ and $19.4 \pm 0.6 \mathrm{nM}$, respectively (Figure 3c). These results agreed well with published $K_{\mathrm{D}}$ values. ${ }^{56}$ Interestingly, the meFab/MPL-PAGFP complex bound to significantly fewer receptors (Figure $3 \mathrm{~d}$, top). A spatial model based on atomic coordinates suggests that this difference in density reflects a steric component (Figure 3b). Of note, trastuzumab binds to domain IV of HER2, which is adjacent to the cell membrane.

To test whether this difference reflects unique populations (e.g., monomeric vs clustered HER2), cell lines were pretreated with saturating levels of trastuzumab meFab/ MPL-eGFP. Next, the less "bulky" trastuzumab meFab/MAF647 complex was added to identify and quantify the remaining, unbound receptors. While the meFab/M-AF647 bound to fewer sites, it did not exclusively target isolated monomeric receptors (Figure $3 \mathrm{~d}$, bottom). This observation suggests that HER2, monomeric or clustered, likely exists in multiple, distinct environments. Likewise, post-translational modifications within the receptor could also affect this distribution. Of note, aberrant glycosylation of receptors is frequently observed and has been implicated in resistance to $\mathrm{mAb}$ therapeutics in patients. ${ }^{57,58}$ We plan to investigate the biological impact of these differences in detail in future studies.

We also evaluated the effects of two small molecule drugs, afatinib and paclitaxel on HER2 organization. Both drugs reduced HER2 membrane density but had an opposite effect on HER2 clustering. While afatinib slightly reduced the clustering of HER2, paclitaxel slightly increased the clustering of HER2 (Figure 3d). This proof-of-principle study demonstrates that this method is sensitive to molecular changes in HER2 organization upon exposure to therapeutic agents. In 
the future, our approach may provide unique insights to guide the development of new preclinical candidates.

We extended our method to other growth factor receptors, and imaged HER3 and EGFR using duligotuzumab. In two cell lines, the incubation of bivalent duligotuzumab memAb, compared to monovalent duligotuzumab meFab, led to an increase in receptor clustering. This is consistent with previous data wherein the multimerization of a HER2 aptamer improves binding and avidity. ${ }^{59}$ In contrast, pretreatment of cells with cetuximab Fab (masking EGFR sites) resulted in a decrease in receptor clustering and density. As expected, this suggests the presence of HER3 clusters in addition to HER3-EGFR and/or EGFR-EGFR clusters. Cumulatively, these results highlight the sensitivity of our approach in detecting the formation of biologically relevant receptor clusters.

Finally, we compared SAMI-qSMLM detected densities of growth factor receptors in three cell lines to published values from flow cytometry. ${ }^{48}$ We recognize that SAMI-qSMLM densities may not be absolute. For example, a number of experimental details including receptor downregulation upon Fab binding in live cells could play a role in receptor counting. Still, our detected densities show excellent correlation with published data ${ }^{48}$ and suggest the utility of the approach in biology. In the future, SAMI-qSMLM could be readily applied to drug discovery and the molecular characterization of specific therapeutic targets.

\section{CONCLUSION}

The strength of our approach lies in its versatility. Any SMLM microscope, imaging condition, imaging method, fluorescent probe, or localization software can be used with SAMI. Moreover, no advance knowledge of fluorophore photokinetics is required. By combining SAMI with meditope technology, endogenous proteins can be robustly detected. Beyond the imaging of cells, meditope based constructs could make excellent probes for future precision medicine applications. Our approach has been designed to assess the clustering and density of membrane proteins, but in principle can be extended to probe other cellular molecules of interest.

\section{MATERIALS AND METHODS}

His-Tagged PEG Synthesis. Standard solid-phase N- $\alpha$ Fmoc chemistry was used to synthesize PEG-His ${ }_{6}$ peptide on a CS136XT peptide synthesizer (C S BIO, Menlo Park, CA) at the City of Hope Peptide Synthesis Core. $\mathrm{mPEG}_{4}$-NHS was purchased from ChemPep Inc. (Wellington, FL). PEG-His ${ }_{6}$ (mPEG4-HHHHHH) was obtained at $>95 \%$ purity, and characterized by LTQ-FT mass spectrometry (1103.5 $\left[\mathrm{M}+\mathrm{H}^{+}\right]$; calcd $\left.1103.5\left[\mathrm{M}+\mathrm{H}^{+}\right]\right)$.

Meditope-Alexa Fluor 647 (M-AF647) Synthesis. Standard solid-phase $\mathrm{N}-\alpha$ Fmoc chemistry was used to synthesize meditope derivatives on the CS136XT peptide synthesizer (C S BIO). After cleavage of the peptides from resin using reagent $\mathrm{K}$ (TFA/water/ phenol/thioanisole/EDT $=82.5: 5: 5: 5: 2.5)$, crude peptides were collected by precipitation from cold ether. For disulfide-linked meditopes, a further oxidation using either $20 \%$ DMSO in ammonium acetate buffer $(\mathrm{pH} 6)$ or iodine was performed. All peptides were purified using a reverse-phase HPLC (Agilent 1200 system with Agilent prep-C18 column, $21.2 \times 150 \mathrm{~mm}, 5 \mu \mathrm{m})$ with a water $(0.1 \%$ TFA)/acetonitrile ( $0.1 \%$ TFA) solvent system. All peptides were characterized by mass spectrometry. Alexa Fluor 647 labeled peptides were synthesized from Alexa Fluor 647-NHS (Thermo Fisher Scientific, Waltham, MA). Reverse-phase HPLC purification provided the purified M-A647: Ac-CQFDXSTRRLRCGGSK-A647 (X = diphenylalanine). ${ }^{34}$
Molecular Biology. The plasmid encoding $\mathrm{His}_{6}$-eGFP(A206K) in a pRSETa vector (Figure S1) was generated in two steps. First, we inserted two bases before a BamHI site into the $\mathrm{His}_{6}$-PA-GFP(A206 $\mathrm{K})$ construct in the pRSETa vector using the Phusion Site-Directed Mutagenesis Kit (Finnzymes, Thermo Fisher Scientific). AAGGATCGATGGaaGGATCCATGGT (forward) and ATCGTCATCGTCGTACAGATCCCG (reverse) primers were used. Next, we exchanged PA-GFP(A206K) with eGFP(A206K) in an N1 vector using BamHI/BsrGI restriction enzyme sites; this completed our working $\mathrm{His}_{6}$-eGFP(A206K) construct. Ensuring that all generated proteins had the same linker, we used our working construct $\left(\mathrm{His}_{6}\right.$ eGFP(A206K) in a pRSETa vector) as a template to make His $_{6}$-PAGFP(A206K) and $\mathrm{His}_{6}$-PA-mCherryl constructs by exchanging the eGFP(A206K) with PA-GFP(A206K) and PA-mCherryl from an N1 vector using $\mathrm{Bam} \mathrm{HI} / \mathrm{BsrGI}$ restriction enzyme sites.

Fluorescent and Optical Highlighter Protein Purification. Proteins in the pRSETa vector were transformed into BL21 cells. Cells were grown in LB (Luria-Bertani, Thermo Fisher Scientific) medium with appropriate antibiotic selection, induced with $0.5 \mathrm{mM}$ isopropyl-thio- $\beta$-D-galactopyranoside (IPTG, RPI, Mount Prospect, $\mathrm{IL})$ at an optical density $\left(\mathrm{OD}_{600}\right)$ of 0.8 , and harvested after a $4 \mathrm{~h}$ incubation at $30{ }^{\circ} \mathrm{C}$. Cell pellets were stored at $-80^{\circ} \mathrm{C}$. Proteins were purified using affinity chromatography followed by size exclusion chromatography. HisPur cobalt resin (Thermo Fisher Scientific) and a Superose 6 10/300 GL column (GE Healthcare, Pittsburgh, PA) connected to an AKTA FPLC system (GE Healthcare) were used. Monomeric proteins were eluted at the correct size. When appropriate, the His-tag was cleaved using enterokinase (ABM, Richmond, Canada) according to manufacturer recommendations. HisPur cobalt resin was used to remove cleaved His-tag following enterokinase cleavage. Coomassie stained SDS-PAGE gels of pure proteins are shown in Figure S2a.

Trastuzumab meFab/Meditope-Alexa Fluor 647, Duligotuzumab meFab/Meditope-Alexa Fluor 647, and Duligotuzumab memAb/Meditope-Alexa Fluor 647. Duligotuzumab meFab, duligotuzumab memAb, and trastuzumab meFabI $83 \mathrm{E}^{34}$ (referred to here as trastuzumab meFab) were obtained as described before. ${ }^{28}$ Purity and masses of memAb/meFab constructs were confirmed by performing nonreducing and reducing SDS PAGE. A 10-fold excess of M-AF647 was complexed with meFabs or memAb for $30 \mathrm{~min}$ at room temperature. The complex was passed through a Biospin $\overline{P \overline{6}}$ column (Bio-Rad, Hercules, CA) to remove excess dye. Freshly prepared complex was used in all experiments.

MPL-PA-GFP and MPL-eGFP. MPL-PA-GFP and MPL-eGFP were expressed and purified similarly as previously described for MPL-GFP, ${ }^{29}$ with the exception that HisPur cobalt resin was used for the initial affinity purification step and for the reverse affinity purification step after $\mathrm{His}_{6}$-SMT3 tag cleavage by ULP1. Protein was purified in the dark and used for experiments immediately after purification. A Coomassie stained SDS-PAGE gel of pure MPL-PAGFP is shown in Figure S2b. Trastuzumab meFab was incubated with excess MPL-PA-GFP and the 1:1 meFab/MPL-PA-GFP complex was separated by analytical size exclusion chromatography (SEC). Freshly prepared complex was used in all experiments.

Fluorescent Labeling of Antibodies. Mouse monoclonal antiGFP (ab1218) and anti-RFP (ab125244) antibodies were purchased from Abcam (Cambridge, United Kingdom). Anti-GFP antibody was labeled with Alexa Fluor 647 NHS ester (Life Technologies) and antiRFP antibody was labeled with Atto 488 NHS ester (Sigma-Aldrich, St. Louis, MO) according to manufacturer instructions. Briefly, a solution containing a 6-10 molar excess of dye dissolved in dimethyl sulfoxide (DMSO) was mixed with a solution of $1 \mathrm{mg} / \mathrm{mL}$ antibody in PBS pH 7.4 with $0.02 \mathrm{M} \mathrm{NaHCO}_{3}$. The resulting solution was allowed to react for $30 \mathrm{~min}$ at room temperature. The solution was quenched with $1.5 \mathrm{M}$ hydroxylamine $(\mathrm{pH} 8.5)$ for $10 \mathrm{~min}$. Unconjugated dye was removed by passing the solution through a size exclusion chromatography column (Bio-Rad). Prior to the experiment, labeled antibody was passed through a $300 \mathrm{kDa}$ concentrator to remove any potential aggregates. The concentration of labeled antibodies was measured by a NanoDrop 1000 (Thermo 
Fisher Scientific) and calculated with respect to the specific dye correction factor. Approximately one to two dyes per antibody on average were obtained in all cases.

SPR Binding Assays. SPR experiments were performed on the Biacore T100 (GE Healthcare) instrument. For trastuzumab meFab, we used HBS-EP+ (GE Healthcare) as a running buffer at $25^{\circ} \mathrm{C}$. The extracellular portion of HER $2^{28}$ was immobilized to a series S CM5 sensor chip using standard amine coupling chemistry at densities suitable for kinetic experiments. Trastuzumab meFab was prepared as 2-fold serial dilutions from $10 \mathrm{nM}$ to $78 \mathrm{pM}$ concentrations. Trastuzumab meFab was incubated with excess MPL-PA-GFP and the $1: 1$ complex was isolated by SEC. This complex was also prepared as 2 -fold serial dilutions from $10 \mathrm{nM}$ to $78 \mathrm{pM}$ and passed over the HER2 surface at a $30 \mu \mathrm{L} / \mathrm{min}$ flow rate allowing for a $120 \mathrm{~s}$ association phase and a $600 \mathrm{~s}$ dissociation phase. Each sample concentration was run in triplicate. Regeneration of the surface was accomplished with pulses of glycine $\mathrm{pH}$ 2.0. Each data set was fit to a 1:1 kinetic binding model using BiaEvaluation software. The reported dissociation constants of $43 \pm 2 \mathrm{pM}$ for the Fab alone and $71 \pm 2 \mathrm{pM}$ for the trastuzumab meFab/MPL-PA-GFP complex binding to immobilized HER2 are the averaged values of the triplicate data sets with standard deviations (Figure S9).

Meditope binding to duligotuzumab memAb was confirmed via SPR analysis using a GE Healthcare Life Sciences Biacore T100 instrument as described previously. ${ }^{34}$ Briefly, duligotuzumab memAb was diluted to $5 \mu \mathrm{g} / \mathrm{mL}$ in $10 \mathrm{mM}$ sodium acetate $\mathrm{pH} 5.5$ buffer (GE Healthcare Life Sciences) and covalently immobilized to a series $S$ CM5 sensor chip (GE Healthcare Life Sciences) using aminecoupling chemistry to produce $R_{\max }$ values of $2000 \mathrm{RU}$ using the equation: $R_{\mathrm{L}}=R_{\max } \times\left(\right.$ ligand $_{\mathrm{MW}} /$ analyte $\left._{\mathrm{MW}}\right) \times 1 / S_{\mathrm{m}}$, where $S_{\mathrm{m}}$ is the stoichiometric ratio and $R_{\mathrm{L}}$ is the immobilization level. Meditope peptide was diluted in $1 \times$ HBS-EP+ buffer (GE Healthcare Life Sciences) and flowed over the immobilized duligotuzumab memAb at a flow rate of $30 \mu \mathrm{L} / \mathrm{min}$ followed by $10 \mathrm{mM}$ glycine $\mathrm{pH} 2.0$ regeneration buffer at $37{ }^{\circ} \mathrm{C}$. Kinetic constants were calculated using the 1:1 binding model using the BiaEvaluation software. Triplicate runs were used to characterize a $K_{\mathrm{D}}$ of $1.2 \mathrm{nM}\left(k_{\mathrm{on}}=2.8 \mathrm{M}^{-1} \mathrm{~s}^{-1}\right.$ and $k_{\text {off }}=3.3 \times 10^{-4} \mathrm{~s}^{-1}$ ) for the binding of meditope to duligotuzumab memAb. Data is shown in Figure S1la.

FACS. Duligotuzumab memAb binding to cells expressing EGFR and HER3 receptors was determined by florescence-activated cell sorting (FACS) as previously described in detail. ${ }^{28}$ Briefly, adherent MDA-MB-468 cells were solubilized with Trypsin/EDTA (Thermo), washed $3 \mathrm{x}$ with PBS containing $1 \%$ BSA and resuspended in PBS containing $1 \%$ BSA at a final concentration of $1 \times 10^{6}$ cells $/ \mathrm{mL}$. To characterize antigen binding, cells were then incubated with $100 \mathrm{nM}$ duligotuzumab memAb in PBS/BSA for $30 \mathrm{~min}$ followed by a washing $3 \mathrm{x}$ with PBS/BSA. Secondary labels, either one equivalent (1 $\mu \mathrm{L} / \mathrm{mL}$ ) of goat antihuman-Fc IgG labeled with AF-488 or $5 \mathrm{~mol}$ equiv of meditope-AF647, were added to all but one control sample, incubated for $30 \mathrm{~min}$ and subsequently washed $3 \times$ with PBS/BSA. Controls were handled identically to the treatment samples with PBS substituting the volumes of $\mathrm{mAb}$ or secondary antibody added. DAPI $(0.1 \mu \mathrm{g} / \mathrm{mL}$, final concentration) was added $10 \mathrm{~min}$ prior to analysis to gate for nonviable cells, with the exception of one sample used to control background fluorescence. FACS was performed using a CyAn ADP Analyzer (Beckman Coulter), and the data were analyzed using Flowjo software. Mean fluorescence intensity (MFI) shifts were apparent for duligotuzumab memAb using both secondary techniques.

Surface Preparation. $25 \mathrm{~mm}$ \#1.5 coverslips (Warner Instruments, Hamden, CT) were cleaned as previously described. ${ }^{60}$ As shown in Scheme S1, His-tagged proteins were covalently attached to diazotized surfaces. Surfaces were first incubated with concentrated $\mathrm{HCl}$ for $2 \mathrm{~min}$, followed by several rinses with distilled water and absolute ethanol. The surfaces were then treated with $9.4 \mathrm{mM} \mathrm{p}$ aminophenyltrimethoxysilane in absolute ethanol for $30 \mathrm{~min}$ at room temperature. Surfaces were subsequently rinsed with absolute ethanol 3 times $(3 x)$ and allowed to air-dry. This was followed by incubation with a solution containing $260 \mathrm{mM} \mathrm{HCl}$ and $5.2 \mathrm{mM} \mathrm{NaNO}_{2}$, in distilled water, for $30 \mathrm{~min}$ at $4{ }^{\circ} \mathrm{C}$. Diazotized surfaces were then washed with cold sodium acetate buffer ( $50 \mathrm{mM}, \mathrm{pH} 4.7)$, 3 times for 3 min each, followed by several washes with cold distilled water and cold phosphate buffered saline (PBS, pH 7.4). Surfaces were placed on parafilm and immediately incubated with either His-tagged proteins (combined with the appropriate concentration of PEG$\mathrm{His}_{6}$ ) or $50 \mu \mathrm{M} \mathrm{PEG}-\mathrm{His}_{6}$ alone for $30 \mathrm{~min}$ at room temperature. After rinsing several times with PBS, surfaces were quenched with 50 $\mu \mathrm{M}$ PEG-His ${ }_{6}$ for $30 \mathrm{~min}$ at room temperature, and finally rinsed with PBS. Freshly prepared surfaces were used for experiments.

AF647 and A488 labeled antibodies were used to detect surface attached PA-GFP and PA-mCherry1, respectively. Following the attachment of $3 \mathrm{nM} \mathrm{His} 6$-PA-GFP or $\mathrm{His}_{6}$-PA-mCherry1 (combined with $300 \mathrm{nM}$ PEG-His ${ }_{6}$ ), surfaces were washed $3 \times$ with blocking buffer (BB, 5\% BSA in PBS) for 5 min each. After washing, surfaces were incubated for $1 \mathrm{~h}$ at room temperature with $2 \mu \mathrm{g} / \mathrm{mL}$ of fluorescently labeled antibody in BB. Post incubation, surfaces were rinsed $1 \times$ with $\mathrm{BB}$ and $2 \times$ with $0.1 \%$ Tween 20 in PBS for $5 \mathrm{~min}$ each. As a control, $50 \mu \mathrm{M}$ or $300 \mathrm{nM}$ PEG-His ${ }_{6}$ surfaces were incubated with labeled antibodies using the same conditions. All surfaces were rinsed with PBS and DSTORM imaging immediately followed.

Trastuzumab meFab/M-AF647 was used to detect surfaces prepared with $10 \mathrm{nM}$ HER2 (combined with $1 \mu \mathrm{M}$ PEG-His ${ }_{6}$ ) or $30 \mathrm{nM}$ HER2 (combined with $3 \mu \mathrm{M}$ PEG-His 6 ). Extracellular Histagged HER2 was obtained as before. ${ }^{28}$ Following protein attachment, surfaces were washed $3 \times$ with PBS and incubated with $100 \mathrm{nM}$ trastuzumab meFab/M-AF647 complex in PBS for $10 \mathrm{~min}$ at $37^{\circ} \mathrm{C}$. As a control, $50 \mu \mathrm{M}$ PEG-His ${ }_{6}$ surfaces were incubated with $100 \mathrm{nM}$ trastuzumab meFab/M-AF647 complex using the same conditions. All surfaces were rinsed with PBS and DSTORM imaging immediately followed. To calculate $\alpha$ for duligotuzumab meFab/M-AF647 and duligotuzumab memAb/M-AF647, we used EGFR (R\&D Systems, Minneapolis, MN) coated surfaces. Experiments with 30 nM EGFR (combined with $3 \mu \mathrm{M}$ PEG-His ${ }_{6}$ ) were performed similarly as reported for trastuzumab meFab/M-AF647. Using SAMI, duligotuzumab meFab/M-AF647 resulted in an $\alpha=2$ and duligotuzumab memAb/M-AF647 in an $\alpha=4$. The difference in $\alpha$ corresponds with two AF647 molecules attached to the memAb and only one AF647 molecule attached to the meFab.

Cell Culture and Imaging of Endogenous Growth Factor Receptors in Cells. SK-BR-3, BT-474, and MDA-MB-468 cell lines were purchased from the American Type Culture Collection (American Type Culture Collection (ATCC), Manassas, VA). Cells were cultured in Phenol red-free Dulbecco's Modified Eagle Medium (DMEM) supplemented with $10 \%$ fetal bovine serum, $1 \mathrm{mM}$ sodium pyruvate, 100 units $/ \mathrm{mL}$ penicillin, 100 units $/ \mathrm{mL}$ streptomycin, and 2 $\mathrm{mM}$ L-alanyl-L-glutamine. For SMLM, cells were grown on coverslips coated with fibronectin-like engineered protein $(25 \mu \mathrm{g} / \mathrm{mL}$ in PBS, $\mathrm{pH}$ 7.4, Sigma-Aldrich) as described before. ${ }^{41}$

For imaging experiments, cells were washed with PBS at $37^{\circ} \mathrm{C}$ and incubated with $100 \mathrm{nM}$ trastuzumab meFab/MPL-PA-GFP (30 min at $37{ }^{\circ} \mathrm{C}$ in media), trastuzumab meFab/M-AF647 $\left(10 \mathrm{~min}\right.$ at $37{ }^{\circ} \mathrm{C}$ in media), $100 \mathrm{nM}$ duligotuzumab meFab/M-AF647 (10 min at 37 ${ }^{\circ} \mathrm{C}$ in media), or $100 \mathrm{nM}$ duligotuzumab memAb/M-AF647 (10 min at $37^{\circ} \mathrm{C}$ in media). As a control, cells were incubated with $100 \mathrm{nM}$ M-A647 or $100 \mathrm{nM}$ MPL using the same conditions. No appreciable signal was detected in either case. To identify HER2 receptors undetected by the trastuzumab meFab/MPL-PA-GFP complex, cells were incubated with $100 \mathrm{nM}$ trastuzumab meFab/MPL-GFP (for 30 min at $37{ }^{\circ} \mathrm{C}$ in media), washed with media, and subsequently incubated with $100 \mathrm{nM}$ trastuzumab meFab/M-AF647 (10 min at 37 $\left.{ }^{\circ} \mathrm{C}\right)$. To test for the effects of afatinib ${ }^{46,48}$ (Selleck USA) or paclitaxel $^{48}$ (Thermo Fisher Scientific) on HER2 organization and density, BT-474 cells were first treated with $100 \mathrm{nM}$ of either drug for $2 \mathrm{~h}$ at $37{ }^{\circ} \mathrm{C}$ in media, washed with media, and subsequently incubated with $100 \mathrm{nM}$ trastuzumab meFab/M-AF647 (10 min at 37 ${ }^{\circ} \mathrm{C}$ in media). To block EGFR receptors and detect available HER3 receptors, cells were first treated with $100 \mathrm{nM}$ cetuximab (BristolMyers Squibb) Fab for $30 \mathrm{~min}$ at $37^{\circ} \mathrm{C}$ in media, washed with media, and subsequently incubated with $100 \mathrm{nM}$ duligotuzumab meFab/M- 
AF647 $\left(10 \mathrm{~min}\right.$ at $\left.37^{\circ} \mathrm{C}\right)$ or $100 \mathrm{nM}$ duligotuzumab memAb/MAF647 $\left(10 \mathrm{~min}\right.$ at $\left.37^{\circ} \mathrm{C}\right)$. For all experiments, cells were rinsed $3 \mathrm{x}$ with PBS at $37{ }^{\circ} \mathrm{C}$ and fixed as described previously. ${ }^{41}$

Super-Resolution Effective $K_{\mathrm{D}}$ Measurements. Thirty $\mathrm{nM}$ His $_{6}$-HER2 combined with $3 \mu \mathrm{M}$ PEG-His ${ }_{6}$ was used to prepare surfaces as described above. Various concentrations of freshly prepared trastuzumab meFab/MPL-PA-GFP complex (3-300 nM) were incubated with HER2 surfaces (in PBS) or with SK-BR-3 cells (in media) at $37{ }^{\circ} \mathrm{C}$ for $30 \mathrm{~min}$. Alternatively, various concentrations of freshly prepared trastuzumab meFab/M-A647 complex (1-300 $\mathrm{nM})$ were incubated with BT- 474 cells $\left(10 \mathrm{~min}\right.$ at $37{ }^{\circ} \mathrm{C}$ in media). Cells were quickly washed with PBS at $37{ }^{\circ} \mathrm{C}$, fixed and imaged. Between 3 and 7 measurements were performed on HER2 surfaces incubated with different concentrations of trastuzumab meFab/MPLPA-GFP $(N=7$ for $3 \mathrm{nM} ; N=7$ for $10 \mathrm{nM} ; N=3$ for $30 \mathrm{nM} ; N=6$ for $100 \mathrm{nM} ; N=3$ for $300 \mathrm{nM}$; Figure S10). Between 6 and 16 cells were acquired for SK-BR-3 cells incubated with different concentrations of trastuzumab meFab/MPL-PA-GFP (6 cells and 16 ROIs for $3 \mathrm{nM} ; 7$ cells and 16 ROIs for $10 \mathrm{nM} ; 7$ cells and 14 ROIs for 30 nM; 14 cells and 28 ROIs for $100 \mathrm{nM} ; 16$ cells and 17 ROIs for 300 $\mathrm{nM}$; Figure $3 \mathrm{~b}$ and Figure S10). Between 10 and 15 cells were acquired for BT-474 cells incubated with different concentrations of trastuzumab meFab/M-AF647 ( 12 cells and 48 ROIs for $1 \mathrm{nM} ; 12$ cells and 35 ROIs for $3 \mathrm{nM}$; 10 cells and 37 ROIs for $10 \mathrm{nM} ; 10$ cells and 38 ROIs for $30 \mathrm{nM}$; 15 cells and 45 ROIs for $100 \mathrm{nM} ; 13$ cells and 39 ROIs for $300 \mathrm{nM}$; Figure $3 \mathrm{~b}$ ). In MATLAB, binding curves and effective $K_{\mathrm{D}}$ values were estimated using the following equation $y=\frac{N_{\text {sat }}}{\left(1+\frac{K_{\mathrm{D}}}{[\text { ligand] }]}\right)}$ as reported before. ${ }^{61}$ The Hill coefficient was set to 1 for reported curves.

Optical Setup and Image Acquisition. PALM and dSTORM imaging were performed on a 3D N-STORM super-resolution microscope (Nikon). The N-STORM system (Nikon Instruments) consists of a fully automatic Ti-E inverted microscope with a piezo stage on a vibration isolation table. This system includes a $100 \times 1.49$ NA TIRF objective (Apo), N-STORM lens, $\lambda / 4$ plate, and Quad cube C-NSTORM (97355 Chroma). The microscope has a Perfect Focus Motor to maintain imaging at the focal plane of interest, an MLCMBP-ND laser launch with 405, 488, 561, and $647 \mathrm{~nm}$ lasers (Agilent), and an EM-CCD camera iXon DU897-Ultra (Andor Technology, South Windsor, CT).

PALM image acquisition: Images of $27 \times 27 \mu \mathrm{m}$ were collected with an exposure time of $100 \mathrm{~ms}$ using the software Andor SOLIS for Imaging X-07779 (Andor Technology). The image pixel size was $106.7 \mathrm{~nm}$. PA-GFP was simultaneously activated and excited using the $488 \mathrm{~nm}$ laser with the power set to within the range of $1.45-1.9 \mathrm{~mW}$ (measured out of the optical fiber). Imaging was done until PA-GFP was completely exhausted, typically acquiring 20000 frames. PAmCherryl was activated with the $405 \mathrm{~nm}$ laser and excited with the $561 \mathrm{~nm}$ laser, and laser powers were set to within $0.01-0.02 \mathrm{~mW}$ and 1.45-1.6 mW, respectively. TetraSpeck beads (Life Technologies) were used as fiducial markers for drift correction following PALM acquisition.

dSTORM image acquisition: Images of $41 \times 41 \mu \mathrm{m}$ were collected with an exposure time of $10 \mathrm{~ms}$ using the NIS-Elements 4.3 Software (Nikon). The image pixel size was $160 \mathrm{~nm}$. The $647 \mathrm{~nm}$ laser power to activate/excite $\mathrm{A} 647$ was set to $118 \mathrm{~mW}$ and the $488 \mathrm{~nm}$ laser power to activate/excite Atto 488 was set to $55 \mathrm{~mW} .20000$ to 40000 frames were usually acquired. Drift correction was performed using custom-written MATLAB code. Surfaces were imaged immediately after preparation in Attofluor cell chambers (Life Technologies) in 50 $\mathrm{mM}$ Tris ( $\mathrm{pH} 8.0$ ), $10 \mathrm{mM} \mathrm{NaCl}$, and $10 \%$ glucose imaging buffer containing mercaptoethylamine (MEA, $100 \mathrm{mM})$ and GLOX (10\% $\mathrm{v} / \mathrm{v})$ as previously described. ${ }^{4}$

Average localization precisions for PALM and dSTORM cell experiments are provided in Table S1.

TIRF imaging was performed on the same microscope system described for SMLM. Images were collected using NIS-Elements 4.3 Software and eGFP was excited using the $488 \mathrm{~nm}$ laser with a power of $5 \mathrm{~mW}$ (measured out of the optical fiber). Molecules were counted using the IDL software PeakSelector (Research Systems, Inc.). ${ }^{39}$ Similar results were obtained when molecules were counted in ImageJ. The $P$ value between detected molecules in PALM and TIRF was 0.4 from both PeakSelector and Image J counting (no significant difference).

Counting Molecules. Localizations from PALM images were first localized using PeakSelector software. ${ }^{39}$ For each image, the distribution of the localization precision $(\sigma)$ was used to estimate a Group Radius (GR) value as $3 \times \sigma_{\mathrm{MAX}}$, where $\sigma_{\mathrm{MAX}}$ represents the value encompassing $98 \%$ of the total number of localizations. Localizations were subsequently grouped using custom-written code in MATLAB (The Mathworks, Inc., Natick, MA) as previously described. ${ }^{62}$ Localizations associated with a single molecule were grouped together based on their spatial and temporal information, such that the distance between two localizations in a molecule was not greater than GR, and the blinking time of a molecule was not greater than a given dark time $t_{\mathrm{D}}$. After localizations were identified in this manner, i.e., assigned to a particular molecule, the location of each molecule center was computed by taking into account the number of photons and localization precision uncertainties of the localization centers associated with each molecule. In this way, given a specific dark time, we could estimate the number and location of blinking molecules. By plotting the density of localizations as a function of dark time $\left(t_{\mathrm{D}}\right)$ (Figure 1a,b, Figure 2a-c, Figure $S 4$ and 5 ), we were able to identify the maximum dark time $\left(T_{\mathrm{DMAX}}\right) . T_{\mathrm{DMAX}}$ is defined as the value of $t_{\mathrm{D}}$ after which the number of blinking events effectively remains constant. The density of localizations is equal to the density of real detected molecules where $t_{\mathrm{D}}=T_{\mathrm{DMAX}}$. The average number of localizations $\alpha$ is then defined as the ratio between the initial density of localizations $\left(t_{\mathrm{D}}=0\right)$ and the density of real detected molecules $\left(t_{\mathrm{D}}\right.$ $\left.=T_{\text {DMAX }}\right)$. For PALM, the localization density as a function of $t_{\mathrm{D}}$ can be fit to the semiempirical equation ${ }^{2}$ (Figure la,b):

$$
N\left(t_{\mathrm{D}}\right)=N \times\left(1+n_{\mathrm{BLINK}} \times e^{1-t_{\mathrm{D}} / t_{\mathrm{OFF}}}\right)
$$

For localization detection in dSTORM, NIS-Elements software was used with the following identification settings: 700 as the minimum number of photons/localization, $200 \mathrm{~nm}$ minimum localization width, $400 \mathrm{~nm}$ maximum localization width, $300 \mathrm{~nm}$ initial fit width, 1.3 maximum axial ratio, and 1 pixel maximum displacement. Using custom-written code in MATLAB, processed data could then be analyzed as just described for PALM to estimate $T_{\mathrm{DMAX}}$ and $\alpha$ (Figure $2 a-c)$.

Pair-Correlation Image Analysis. Using the appropriate $\alpha$ for each fluorophore, protein distribution parameters are estimated using pair-correlation (PC) analysis, as previously described. ${ }^{9,36,41}$ Molecular density and autocorrelation functions were calculated from square areas of $164 \mu \mathrm{m}^{2}$ for PALM surfaces, $369 \mu \mathrm{m}^{2}$ for dSTORM surfaces, and $10-18 \mu \mathrm{m}^{2}$ for cells (both PALM and dSTORM images). The overall nano-organization and molecular distribution parameters, such as the number of detected molecules in a cluster and the cluster radius, are extracted from individual correlation curves. Random monomers and proteins sparsely distributed on surfaces have no spatial correlation, and thus yield a correlation function with an average equal to approximately 1 . Proteins organized into clusters, however, have short-length correlations and result in a correlation function with an initial amplitude greater than 1, followed by an exponential decay. Pair-correlation methodology can reliably analyze random monomers and clusters with as few as two molecules. ${ }^{9,36}$ Further, reliable analysis is possible on clusters with as many as $10^{62}$ or more molecules (our unpublished data has characterized CD3 complexes with up to 20 molecules).

For PALM analysis, single localizations were removed (approximately $5-7 \%$ of the total localizations in the image). Two data sets were prepared in PeakSelector, one containing the spatial coordinates of all identified localizations and another containing the coordinates of grouped localizations. Comparison of the two data sets provided for the removal of single localizations with the same coordinates (i.e., 
duplicate localizations from the grouping process). This process did not affect the results of PC analysis (Figure S7).

A k-means-like clustering algorithm ${ }^{62}$ was used to quantify the fraction of clustered and unclustered receptors (monomers) in a given square region of interest (ROI). This algorithm uses the average localization precision, cluster radius from PC analysis, and maximum fluorophore dark time $\left(T_{\mathrm{DMAX}}\right)$ to define molecule clusters within each ROI. Molecules are counted as part of a cluster if these spatiotemporal requirements are met. Otherwise, molecules are labeled as unclustered monomers.

\section{ASSOCIATED CONTENT}

\section{S Supporting Information}

The Supporting Information is available free of charge on the ACS Publications website at DOI: 10.1021/jacs.8b04939.

Schematic representation of diazo surface chemistry and His-tagged protein attachment; His-tagged protein construct schematic and SDS-PAGE gels of purified proteins; PC-PALM analysis for proteins on surfaces; Calculation of the maximum dark time and the average number of appearances of photoactivatable proteins; PC-PALM analysis for proteins on cells; Plots for detected density as a function of surface concentration; Surface plasmon resonance results for trastuzumab meFab; Trastuzumab meFab/MPL-PA-GFP binding to HER2 on cells and surfaces; Binding properties of duligotuzumab memAb; Table of average localization precisions obtained in experiments (PDF)

\section{AUTHOR INFORMATION}

\section{Corresponding Author}

*ttalisman@coh.org

\section{ORCID $\odot$}

Devin L. Wakefield: 0000-0002-0914-0558

John C. Williams: 0000-0002-0522-384X

\section{Author Contributions}

${ }^{\dagger}$ O.G. and D.L.W. are equally contributing authors.

\section{Notes}

The authors declare the following competing financial interest(s): D.A.H. and J.C.W. are co-founders, members of the S.A.B., and shareholders of Meditope Biosciences Inc. However, all research and funding was independent of Meditope Biosciences Inc.

\section{ACKNOWLEDGMENTS}

We thank Ms. K. Lennon and Mr. D. Hong for technical help and Dr. I. Talisman for manuscript editing. This work was supported by NCI R21-CA174608 grant (Williams/Talisman), W. M. KECK Medical Foundation grant (Williams/Talisman/ Horne), STOP Cancer Foundation (Talisman), Alicia and John Kruger Funds (Williams), Beckman Research Institute of the City of Hope, and NCI CURE provided for the Eugene and Ruth Roberts Summer Student Academy to R.M.C. and J.G. Research reported in this publication included work performed in the Drug Discovery and Structural Biology Core supported by the National Cancer Institute of the National Institutes of Health under award number P30CA33572. The content is solely the responsibility of the authors and does not necessarily represent the official views of the National Institutes of Health.

\section{REFERENCES}

(1) Sydor, A. M.; Czymmek, K. J.; Puchner, E. M.; Mennella, V. Super-Resolution Microscopy: From Single Molecules to Supramolecular Assemblies. Trends Cell Biol. 2015, 25 (12), 730-48.

(2) Annibale, P.; Vanni, S.; Scarselli, M.; Rothlisberger, U.; Radenovic, A. Quantitative Photo Activated Localization Microscopy: Unraveling the Effects of Photoblinking. PLoS One 2011, 6 (7), e22678.

(3) Lee, S. H.; Shin, J. Y.; Lee, A.; Bustamante, C. Counting single photoactivatable fluorescent molecules by photoactivated localization microscopy (PALM). Proc. Natl. Acad. Sci. U. S. A. 2012, 109 (43), 17436-17441.

(4) Dempsey, G. T.; Vaughan, J. C.; Chen, K. H.; Bates, M.; Zhuang, $\mathrm{X}$. W. Evaluation of fluorophores for optimal performance in localization-based super-resolution imaging. Nat. Methods 2011, 8 (12), 1027-1036.

(5) van de Linde, S.; Wolter, S.; Heilemann, M.; Sauer, M. The effect of photoswitching kinetics and labeling densities on superresolution fluorescence imaging. J. Biotechnol. 2010, 149 (4), 260-6.

(6) Ha, T.; Tinnefeld, P. Photophysics of fluorescent probes for single-molecule biophysics and super-resolution imaging. Annu. Rev. Phys. Chem. 2012, 63, 595-617.

(7) van de Linde, S.; Sauer, M. How to switch a fluorophore: from undesired blinking to controlled photoswitching. Chem. Soc. Rev. 2014, 43 (4), 1076-1087.

(8) Chen, L.; Wang, L.; Shion, H.; Yu, C.; Yu, Y. Q.; Zhu, L.; Li, M.; Chen, W.; Gao, K. In-depth structural characterization of Kadcyla ${ }^{\circledR}$ (ado-trastuzumab emtansine) and its biosimilar candidate. $m A b s$ 2016, 8 (7), 1210-23.

(9) Sengupta, P.; Jovanovic-Talisman, T.; Skoko, D.; Renz, M.; Veatch, S. L.; Lippincott-Schwartz, J. Probing protein heterogeneity in the plasma membrane using PALM and pair correlation analysis. Nat. Methods 2011, 8 (11), 969-975.

(10) Nieuwenhuizen, R. P. J.; Bates, M.; Szymborska, A.; Lidke, K. A.; Rieger, B.; Stallinga, S. Quantitative Localization Microscopy: Effects of Photophysics and Labeling Stoichiometry. PLoS One 2015, 10 (5), e0127989.

(11) Coltharp, C.; Kessler, R. P.; Xiao, J. Accurate Construction of Photoactivated Localization Microscopy (PALM) Images for Quantitative Measurements. PLoS One 2012, 7 (12), e51725.

(12) Lando, D.; Endesfelder, U.; Berger, H.; Subramanian, L.; Dunne, P. D.; McColl, J.; Klenerman, D.; Carr, A. M.; Sauer, M.; Allshire, R. C.; Heilemann, M.; Laue, E. D. Quantitative singlemolecule microscopy reveals that CENP-A(Cnp1) deposition occurs during G2 in fission yeast. Open Biol. 2012, 2, 120078.

(13) Rollins, G. C.; Shin, J. Y.; Bustamante, C.; Presse, S. Stochastic approach to the molecular counting problem in superresolution microscopy. Proc. Natl. Acad. Sci. U. S. A. 2015, 112 (2), E110-8.

(14) Hummer, G.; Fricke, F.; Heilemann, M. Model-independent counting of molecules in single-molecule localization microscopy. Mol. Biol. Cell 2016, 27 (22), 3637-3644.

(15) Karathanasis, C.; Fricke, F.; Gerhard, H.; Heilemann, M. Molecule Counts in Localization Microscopy with Organic Fluorophores. ChemPhysChem 2017, 18 (8), 942-948.

(16) Fricke, F.; Beaudouin, J.; Eils, R.; Heilemann, M. One, two or three? Probing the stoichiometry of membrane proteins by singlemolecule localization microscopy. Sci. Rep. 2015, 5, 14072.

(17) Jungmann, R.; Avendano, M. S.; Dai, M.; Woehrstein, J. B.; Agasti, S. S.; Feiger, Z.; Rodal, A.; Yin, P. Quantitative superresolution imaging with qPAINT. Nat. Methods 2016, 13 (5), 439442.

(18) Schnitzbauer, J.; Strauss, M. T.; Schlichthaerle, T.; Schueder, F.; Jungmann, R. Super-resolution microscopy with DNA-PAINT. Nat. Protoc. 2017, 12 (6), 1198-1228.

(19) Baumgart, F.; Arnold, A. M.; Leskovar, K.; Staszek, K.; Folser, M.; Weghuber, J.; Stockinger, H.; Schutz, G. J. Varying label density allows artifact-free analysis of membrane-protein nanoclusters. Nat. Methods 2016, 13 (8), 661-664. 
(20) Ehmann, N.; van de Linde, S.; Alon, A.; Ljaschenko, D.; Keung, X. Z.; Holm, T.; Rings, A.; DiAntonio, A.; Hallermann, S.; Ashery, U.; Heckmann, M.; Sauer, M.; Kittel, R. J. Quantitative super-resolution imaging of Bruchpilot distinguishes active zone states. Nat. Commun. 2014, 5, 4650.

(21) Spahn, C.; Herrmannsdorfer, F.; Kuner, T.; Heilemann, M. Temporal Accumulation Analysis Provides Simplified Artifact-Free Analysis of Membrane-Protein Nanoclusters. Nat. Methods 2016, 13 (12), 963-964.

(22) Grimm, J. B.; English, B. P.; Chen, J.; Slaughter, J. P.; Zhang, Z.; Revyakin, A.; Patel, R.; Macklin, J. J.; Normanno, D.; Singer, R. H.; Lionnet, T.; Lavis, L. D. A general method to improve fluorophores for live-cell and single-molecule microscopy. Nat. Methods 2015, 12 (3), 244-250.

(23) Lin, Y.; Long, J. J.; Huang, F.; Duim, W. C.; Kirschbaum, S.; Zhang, Y.; Schroeder, L. K.; Rebane, A. A.; Velasco, M. G.; Virrueta, A.; Moonan, D. W.; Jiao, J.; Hernandez, S. Y.; Zhang, Y.; Bewersdorf, $\mathrm{J}$. Quantifying and optimizing single-molecule switching nanoscopy at high speeds. PLoS One 2015, 10 (5), e0128135.

(24) Pennacchietti, F.; Gould, T. J.; Hess, S. T. The Role of Probe Photophysics in Localization-Based Superresolution Microscopy. Biophys. J. 2017, 113 (9), 2037-2054.

(25) Deschout, H.; Cella Zanacchi, F.; Mlodzianoski, M.; Diaspro, A.; Bewersdorf, J.; Hess, S. T.; Braeckmans, K. Precisely and accurately localizing single emitters in fluorescence microscopy. Nat. Methods 2014, 11 (3), 253-66.

(26) Thompson, R. E.; Larson, D. R.; Webb, W. W. Precise nanometer localization analysis for individual fluorescent probes. Biophys. J. 2002, 82 (5), 2775-83.

(27) Lambert, T. J.; Waters, J. C. Navigating Challenges in the Application of Superresolution Microscopy. J. Cell Biol. 2017, 216 (1), 53-63.

(28) Donaldson, J. M.; Zer, C.; Avery, K. N.; Bzymek, K. P.; Horne, D. A.; Williams, J. C. Identification and grafting of a unique peptidebinding site in the Fab framework of monoclonal antibodies. Proc. Natl. Acad. Sci. U. S. A. 2013, 110 (43), 17456-61.

(29) Avery, K. N.; Zer, C.; Bzymek, K. P.; Williams, J. C. Development of a high affinity, non-covalent biologic to add functionality to Fabs. Sci. Rep. 2015, 5, 7817.

(30) Bzymek, K. P.; Avery, K. A.; Ma, Y.; Horne, D. A.; Williams, J. C. Natural and non-natural amino-acid side-chain substitutions: affinity and diffraction studies of meditope-Fab complexes. Acta Crystallogr., Sect. F: Struct. Biol. Commun. 2016, 72 (Pt 11), 820-830.

(31) Bzymek, K. P.; Ma, Y.; Avery, K. A.; Horne, D. A.; Williams, J. C. Cyclization strategies of meditopes: affinity and diffraction studies of meditope-Fab complexes. Acta Crystallogr., Sect. F: Struct. Biol. Commun. 2016, 72 (Pt 6), 434-42.

(32) van Rosmalen, M.; Janssen, B. M.; Hendrikse, N. M.; van der Linden, A. J.; Pieters, P. A.; Wanders, D.; de Greef, T. F.; Merkx, M. Affinity Maturation of a Cyclic Peptide Handle for Therapeutic Antibodies Using Deep Mutational Scanning. J. Biol. Chem. 2017, 292 (4), 1477-1489.

(33) Zer, C.; Avery, K. N.; Meyer, K.; Goodstein, L.; Bzymek, K. P.; Singh, G.; Williams, J. C. Engineering a high-affinity peptide binding site into the anti-CEA mAb M5A. Protein Eng., Des. Sel. 2017, 30, 19.

(34) Bzymek, K. P.; Puckett, J. W.; Zer, C.; Xie, J.; Ma, Y.; King, J. D.; Goodstein, L. H.; Avery, K. N.; Colcher, D.; Singh, G.; Horne, D. A.; Williams, J. C. Mechanically interlocked functionalization of monoclonal antibodies. Nat. Commun. 2018, 9 (1), 1580.

(35) Platonova, E.; Winterflood, C. M.; Junemann, A.; Albrecht, D.; Faix, J.; Ewers, H. Single-molecule microscopy of molecules tagged with GFP or RFP derivatives in mammalian cells using nanobody binders. Methods 2015, 88, 89-97.

(36) Sengupta, P.; Jovanovic-Talisman, T.; Lippincott-Schwartz, J. Quantifying spatial organization in point-localization superresolution images using pair correlation analysis. Nat. Protoc. 2013, 8 (2), 345354.
(37) Schaefer, G.; Haber, L.; Crocker, L. M.; Shia, S.; Shao, L.; Dowbenko, D.; Totpal, K.; Wong, A.; Lee, C. V.; Stawicki, S.; Clark, R.; Fields, C.; Lewis Phillips, G. D.; Prell, R. A.; Danilenko, D. M.; Franke, Y.; Stephan, J. P.; Hwang, J.; Wu, Y.; Bostrom, J.; Sliwkowski, M. X.; Fuh, G.; Eigenbrot, C. A two-in-one antibody against HER3 and EGFR has superior inhibitory activity compared with monospecific antibodies. Cancer Cell 2011, 20 (4), 472-86.

(38) Backlund, M. P.; Lew, M. D.; Backer, A. S.; Sahl, S. J.; Moerner, W. E. The role of molecular dipole orientation in single-molecule fluorescence microscopy and implications for super-resolution imaging. ChemPhysChem 2014, 15 (4), 587-99.

(39) Betzig, E.; Patterson, G. H.; Sougrat, R.; Lindwasser, O. W.; Olenych, S.; Bonifacino, J. S.; Davidson, M. W.; Lippincott-Schwartz, J.; Hess, H. F. Imaging intracellular fluorescent proteins at nanometer resolution. Science 2006, 313 (5793), 1642-1645.

(40) Durisic, N.; Laparra-Cuervo, L.; Sandoval-Alvarez, A.; Borbely, J. S.; Lakadamyali, M. Single-molecule evaluation of fluorescent protein photoactivation efficiency using an in vivo nanotemplate. Nat. Methods 2014, 11 (2), 156.

(41) Tobin, S. J.; Cacao, E. E.; Hong, D. W.; Terenius, L.; Vukojevic, V.; Jovanovic-Talisman, T. Nanoscale effects of ethanol and naltrexone on protein organization in the plasma membrane studied by photoactivated localization microscopy (PALM). PLoS One 2014, 9 (2), e87225.

(42) van Zanten, T. S.; Cambi, A.; Garcia-Parajo, M. F. A nanometer scale optical view on the compartmentalization of cell membranes. Biochim. Biophys. Acta, Biomembr. 2010, 1798 (4), 777-787.

(43) Goswami, D.; Gowrishankar, K.; Bilgrami, S.; Ghosh, S.; Raghupathy, R.; Chadda, R.; Vishwakarma, R.; Rao, M.; Mayor, S. Nanoclusters of GPI-anchored proteins are formed by cortical actindriven activity. Cell 2008, 135 (6), 1085-97.

(44) Zagouras, P.; Rose, J. K. Dynamic equilibrium between vesicular stomatitis virus glycoprotein monomers and trimers in the Golgi and at the cell surface. J. Virol. 1993, 67 (12), 7533-8.

(45) Subik, K.; Lee, J.-F.; Baxter, L.; Strzepek, T.; Costello, D.; Crowley, P.; Xing, L.; Hung, M.-C.; Bonfiglio, T.; Hicks, D. G.; Tang, P. The expression patterns of eR, pR, HeR2, cK5/6, eGFR, Ki-67 and AR by Immunohistochemical Analysis in Breast cancer cell Lines. Breast Cancer: Basic Clin. Res. 2010, 4, 35-41.

(46) Solca, F.; Dahl, G.; Zoephel, A.; Bader, G.; Sanderson, M.; Klein, C.; Kraemer, O.; Himmelsbach, F.; Haaksma, E.; Adolf, G. R. Target binding properties and cellular activity of afatinib (BIBW 2992), an irreversible ErbB family blocker. J. Pharmacol. Exp. Ther. 2012, 343 (2), 342-50.

(47) Slamon, D. J.; Leyland-Jones, B.; Shak, S.; Fuchs, H.; Paton, V.; Bajamonde, A.; Fleming, T.; Eiermann, W.; Wolter, J.; Pegram, M.; Baselga, J.; Norton, L. Use of chemotherapy plus a monoclonal antibody against HER2 for metastatic breast cancer that overexpresses HER2. N. Engl. J. Med. 2001, 344 (11), 783-92.

(48) Stanley, A.; Ashrafi, G. H.; Seddon, A. M.; Modjtahedi, H. Synergistic effects of various Her inhibitors in combination with IGF1R, C-MET and Src targeting agents in breast cancer cell lines. Sci. Rep. 2017, DOI: 10.1038/s41598-017-04301-8.

(49) Wu, Y.; Buranda, T.; Metzenberg, R. L.; Sklar, L. A.; Lopez, G. P. Diazo coupling method for covalent attachment of proteins to solid substrates. Bioconjugate Chem. 2006, 17 (2), 359-365.

(50) Zanacchi, F. C.; Manzo, C.; Alvarez, A. S.; Derr, N. D.; GarciaParajo, M. F.; Lakadamyali, M. A DNA origami platform for quantifying protein copy number in super-resolution. Nat. Methods 2017, 14 (8), 789-792.

(51) Baselga, J.; Swain, S. M. CLEOPATRA: A Phase III Evaluation of Pertuzumab and Trastuzumab for HER2-Positive Metastatic Breast Cancer. Clin. Breast Cancer 2010, 10 (6), 489-491.

(52) Yan, M.; Schwaederle, M.; Arguello, D.; Millis, S. Z.; Gatalica, Z.; Kurzrock, R. HER2 expression status in diverse cancers: review of results from 37,992 patients. Cancer Metastasis Rev. 2015, 34, 157-64.

(53) Huang, X.; Gao, L.; Wang, S.; McManaman, J. L.; Thor, A. D.; Yang, X.; Esteva, F. J.; Liu, B. Heterotrimerization of the growth factor receptors erbB2, erbB3, and insulin-like growth factor-i receptor in 
breast cancer cells resistant to herceptin. Cancer Res. 2010, 70 (3), 1204-14.

(54) Ritter, C. A.; Perez-Torres, M.; Rinehart, C.; Guix, M.; Dugger, T.; Engelman, J. A.; Arteaga, C. L. Human breast cancer cells selected for resistance to trastuzumab in vivo overexpress epidermal growth factor receptor and ErbB ligands and remain dependent on the ErbB receptor network. Clin. Cancer Res. 2007, 13 (16), 4909-19.

(55) Arribas, J.; Baselga, J.; Pedersen, K.; Parra-Palau, J. L. p95HER2 and breast cancer. Cancer Res. 2011, 71 (5), 1515-9.

(56) Troise, F.; Cafaro, V.; Giancola, C.; D’Alessio, G.; De Lorenzo, C. Differential binding of human immunoagents and Herceptin to the ErbB2 receptor. FEBS J. 2008, 275 (20), 4967-79.

(57) Han, X.; Zhang, X.; Li, H.; Huang, S.; Zhang, S.; Wang, F.; Shi, Y. Tunicamycin enhances the antitumor activity of trastuzumab on breast cancer in vitro and in vivo. Oncotarget 2015, 6 (36), 38912-25.

(58) Natoni, A.; Macauley, M. S.; O’Dwyer, M. E. Targeting Selectins and Their Ligands in Cancer. Front. Oncol. 2016, 6, 93.

(59) Mahlknecht, G.; Maron, R.; Schechter, B.; Yarden, Y.; Sela, M. Multimerization of ERBB2/HER2 specific aptamer leads to improved receptor binding. Biochem. Biophys. Res. Commun. 2015, 465 (2), $218-24$.

(60) Jorand, R.; Biswas, S.; Wakefield, D. L.; Tobin, S. J.; Golfetto, O.; Hilton, K.; Ko, M.; Ramos, J. W.; Small, A. R.; Chu, P.; Singh, G.; Jovanovic-Talisman, T. Molecular signatures of mu opioid receptor and somatostatin receptor 2 in pancreatic cancer. Mol. Biol. Cell 2016, 27 (22), 3659-3672.

(61) Dietz, M. S.; Fricke, F.; Kruger, C. L.; Niemann, H. H.; Heilemann, M. Receptor-Ligand Interactions: Binding Affinities Studied by Single-Molecule and Super-Resolution Microscopy on Intact Cells. ChemPhysChem 2014, 15 (4), 671-676.

(62) Rogacki, M. K.; Golfetto, O.; Tobin, S. J.; Li, T.; Biswas, S.; Jorand, R.; Zhang, H.; Radoi, V.; Ming, Y.; Svenningsson, P.; Ganjali, D.; Wakefield, D. L.; Sideris, A.; Small, A. R.; Terenius, L.; JovanovicTalisman, T.; Vukojevic, V. Dynamic lateral organization of opioid receptors (kappa, muwt and muN40D) in the plasma membrane at the nanoscale level. Traffic 2018, 19, 690. 